\title{
Fabrication of three-dimensional bioplotted hydrogel scaffolds for islets of Langerhans transplantation
}

Citation for published version (APA):

Marchioli, G., van Gurp, L., van Krieken, P. P., Stamatialis, D., Engelse, M., van Blitterswijk, C. A., Karperien, M. B. J., de Koning, E., Alblas, J., Moroni, L., \& van Apeldoorn, A. A. (2015). Fabrication of three-dimensional bioplotted hydrogel scaffolds for islets of Langerhans transplantation. Biofabrication, 7(2), [025009]. https://doi.org/10.1088/1758-5090/7/2/025009

Document status and date:

Published: 01/06/2015

DOI:

10.1088/1758-5090/7/2/025009

Document Version:

Publisher's PDF, also known as Version of record

Document license:

Taverne

Please check the document version of this publication:

- A submitted manuscript is the version of the article upon submission and before peer-review. There can be important differences between the submitted version and the official published version of record.

People interested in the research are advised to contact the author for the final version of the publication, or visit the DOI to the publisher's website.

- The final author version and the galley proof are versions of the publication after peer review.

- The final published version features the final layout of the paper including the volume, issue and page numbers.

Link to publication

\footnotetext{
General rights rights.

- You may freely distribute the URL identifying the publication in the public portal. please follow below link for the End User Agreement:

www.umlib.nl/taverne-license

Take down policy

If you believe that this document breaches copyright please contact us at:

repository@maastrichtuniversity.nl

providing details and we will investigate your claim.
}

Copyright and moral rights for the publications made accessible in the public portal are retained by the authors and/or other copyright owners and it is a condition of accessing publications that users recognise and abide by the legal requirements associated with these

- Users may download and print one copy of any publication from the public portal for the purpose of private study or research.

- You may not further distribute the material or use it for any profit-making activity or commercial gain

If the publication is distributed under the terms of Article $25 \mathrm{fa}$ of the Dutch Copyright Act, indicated by the "Taverne" license above, 
PAPER

\section{Fabrication of three-dimensional bioplotted hydrogel scaffolds for islets of Langerhans transplantation}

To cite this article: G Marchioli et al 2015 Biofabrication 7025009

View the article online for updates and enhancements.

\section{Related content}

Fabrication of three-dimensional porous cell-laden hydrogel for tissue engineering Chang Mo Hwang, Shilpa Sant, Mahdokht Masaeli et al.

Yield stress determines bioprintability of hydrogels based on gelatin-methacryloyl and gellan gum for cartilage bioprinting Vivian H M Mouser, Ferry P W Melchels, Jetze Visser et al.

-3D bioprinting of scaffolds with living Schwann cells for potential nerve tissue engineering applications

Liqun Ning, Haoying Sun, Tiphanie Lelong et al.

\section{Recent citations}

\begin{tabular}{l} 
- Bionic Organs: Shear Forces Reduce \\
$\frac{\text { Pancreatic Islet and Mammalian Cell }}{\text { Viability during the Process of 3D }}$ \\
\hline Bioprinting \\
Marta Klak et al \\
- Bioengineered Islet Cell Transplantation \\
Kevin Bellofatto et al \\
- Challenges and solutions for fabrication of \\
$\frac{\text { three-dimensional cocultures of neural }}{\text { cell-loaded biomimetic constructs }}$ \\
Ulises A. Aregueta Robles et al
\end{tabular}

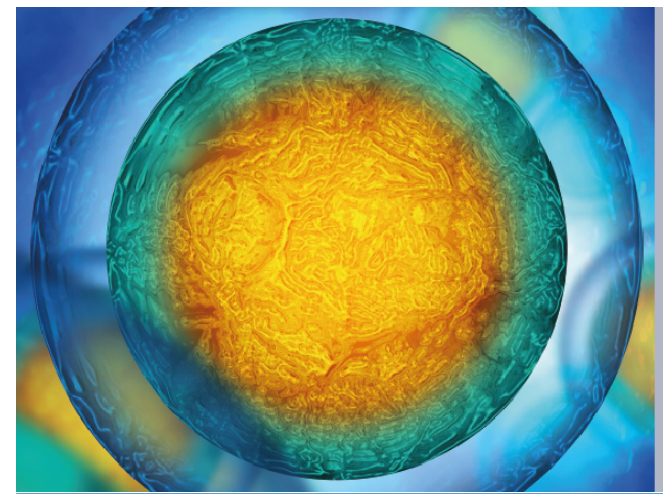

Biophysical Society $\quad$ IOP | ebookS $\overline{\bar{\equiv}}$

Your publishing choice in all areas of biophysics research

Start exploring the collection-download the first chapter of every title for free. 


\title{
Biofabrication
}

\section{PAPER}

CrossMark

\section{Fabrication of three-dimensional bioplotted hydrogel scaffolds for islets of Langerhans transplantation}

23 October 2014

REVISED

20 March 2015

ACCEPTED FOR PUBLICATION

8 April 2015

PUBLISHED

28 May 2015

G Marchioli $^{1,5}$, L van Gurp ${ }^{2}$, P P van Krieken ${ }^{2}$, D Stamatialis ${ }^{6}$, M Engelse $^{3}$, C A van Blitterswijk ${ }^{5}$, M B J Karperien ${ }^{1}$, E de Koning ${ }^{2}$, J Alblas ${ }^{4}$, L Moroni ${ }^{5,7}$ and A A van Apeldoorn ${ }^{1,7}$

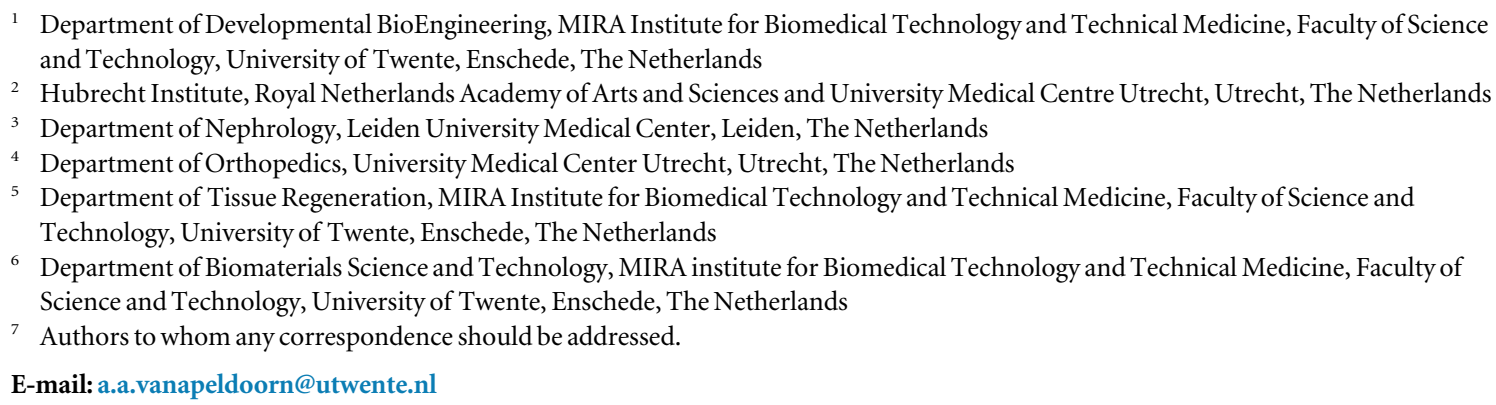

Keywords: type 1 diabetes, beta cells, bioplotting, tissue engineering, islets of Langerhans

Supplementary material for this article is available online

\begin{abstract}
In clinical islet transplantation, allogeneic islets of Langerhans are transplanted into the portal vein of patients with type 1 diabetes, enabling the restoration of normoglycemia. After intra-hepatic transplantation several factors are involved in the decay in islet mass and function mainly caused by an immediate blood mediated inflammatory response, lack of vascularization, and allo- and autoimmunity. Bioengineered scaffolds can potentially provide an alternative extra-hepatic transplantation site for islets by improving nutrient diffusion and blood supply to the scaffold. This would ultimately result in enhanced islet viability and functionality compared to conventional intra portal transplantation. In this regard, the biomaterial choice, the three-dimensional (3D) shape and scaffold porosity are key parameters for an optimal construct design and, ultimately, transplantation outcome. We used 3D bioplotting for the fabrication of a 3D alginate-based porous scaffold as an extra-hepatic islet delivery system. In 3D-plotted alginate scaffolds the surface to volume ratio, and thus oxygen and nutrient transport, is increased compared to conventional bulk hydrogels. Several alginate mixtures have been tested for INS1E $\beta$-cell viability. Alginate/gelatin mixtures resulted in high plotting performances, and satisfactory handling properties. INS1E $\beta$-cells, human and mouse islets were successfully embedded in 3D-plotted constructs without affecting their morphology and viability, while preventing their aggregation. 3D plotted scaffolds could help in creating an alternative extra-hepatic transplantation site. In contrast to microcapsule embedding, in 3D plotted scaffold islets are confined in one location and blood vessels can grow into the pores of the construct, in closer contact to the embedded tissue. Once revascularization has occurred, the functionality is fully restored upon degradation of the scaffold.
\end{abstract}

\section{Introduction}

Islet transplantation is usually performed in a selected group of patients with type 1 diabetes with unstable glycemia characterized by recurrent low blood glucose levels and hypoglycemia unawareness $[1,2]$. However, the efficiency of this procedure is limited: it is estimated that a large proportion of the transplanted islets is destroyed shortly after transplantation $[1,2]$. In addition, long term survival is not optimal as less than $50 \%$ of the patients remain insulin independent after a 5 years follow-up [3]. Several reasons are 
relevant for the adverse outcome of islet transplantation, like: (i) the instant blood mediated inflammatory reaction caused by complement activation and innate immune response [4]; (ii) the disruption of cellextracellular matrix interaction during the isolation phase from the donor pancreas [5-7]; (iii) the loss of islet vasculature, resulting in a reduced nutrient and oxygen supply after transplantation $[8,9]$; (iv) toxins and drugs which are commonly processed in the liver and further cause islet mass decay [10, 11]; (v) alloimmune response; and (vi) recurrent autoimmunity. It is likely that a combination of all these factors is responsible for the reduced graft survival in the long term.

The creation of an extra-hepatic transplantation site, aided by the use of bioengineered implants in which islets are combined with scaffolds, could help overcoming the aforementioned disadvantages. Scaffolds can provide a favorable and protective environment for islets of Langerhans, including the possibility of designing the shape of the construct and functionalizing the material to specifically match the requirements of the embedded cells. Recently, a number of polymeric biomaterials have been used for the creation of porous islet-containing implants. Salt leached porous scaffolds of poly(DL-lactide-co-glycolide) acid (PLGA) [12-14], plotted PLGA scaffolds [15], polydimethylsiloxane salt-leached scaffolds [16, 17] and thermoformed microwell scaffolds of poly(ethylene oxide terephthalate)-poly(butylene terephthalate) (PEOT/PBT) block copolymer [18] are examples of the variety of materials and scaffold shapes used for extra-hepatic islet entrapment and transplantation. Although successful in small animal models, the main disadvantage of such tissue-engineered constructs is the difficulty in scaling them up to a clinically relevant size, containing a therapeutic dosage of islets, without compromising nutrient and oxygen diffusion.

A different approach has been tried by encapsulating islets in hydrogels. Hydrogels are particularly attractive for cell encapsulation and have been used in a variety of applications for soft tissue engineering [19]. Hydrogel encapsulation can be used for immune-protection by preventing contact of the encapsulated cells with the host immune cells. Their mechanical properties and water content closely match the ones of soft tissues in the body [20]. Furthermore, hydrogels can be easily mixed or covalently functionalized with extracellular matrix proteins, peptides and growth factors [21-23]. Among different hydrogel formulations, alginate is a commonly used material for islet encapsulation and has been widely used for immunoprotection of allogeneic transplanted islets from the attack of antibodies and cytokines after transplantation $[3,24,25]$. Islets are either embedded in small alginate beads or mixed in bulk alginate hydrogels, and injected subcutaneously or into the peritoneal cavity $[3,26]$. A study by Ludwig et al reports the fabrication of a oxygenated and immunoprotective alginate-based macro-chamber for islets transplantation in a male patient [27]. In all this cases, the mesh size of the surrounding alginate hydrogel has to be carefully tuned to assure optimal insulin and nutrient diffusion to the embedded islet. At the same time, the hydrogel mesh needs to be tight enough to prevent antibodies and cytokines to interact with the embedded islets [24]. The disadvantage of encapsulation is that the embedded islets cannot be regarded as a single construct but more as a multitude of selfstanding micro organs, which are difficult to implant and be retrieved all at once, if needed.

We studied three-dimensional (3D) bioplotting for the fabrication of an alginate-based, islet-laden $3 \mathrm{D}$ construct. Islets of Langerhans are mixed in the precursor alginate solution and this is plotted in a predefined 3D fashion. Islets are embedded in the hydrogel strands constituting the construct. Such construct can combine the advantages of a tailor made shape and porosity with the beneficial properties of hydrogels in an innovative construct for islet of Langerhans delivery. In contrast to what happens with other constructs or with islet encapsulation in beads, one of the main advantages of this approach is that this type of construct can host a clinically relevant amount of islets in a defined tridimensional, porous construct. In addition, the fabrication of a cell-laden alginate construct can also combine the advantages of a porous hydrogel scaffold with a defined 3D geometry with the immunoprotection properties provided by alginate embedding.

A variety of different techniques has already been developed to tackle the problem of 3D cell-laden hydrogel constructs for several other tissues. Strategies as $3 \mathrm{D}$ plotting and inkjet printing are the most widely used and have been applied to the regeneration of different tissues [28, 29]. 3D deposition of cell-laden hydrogels has been previously investigated for hepatic tissue regeneration [30] and for bone tissue engineering applications [31], showing that a plotted porous structure can be beneficial to enhance cell viability and metabolic activity compared to bulk constructs. 3D hydrogel deposition has been also applied to the fabrication of aortic valves [32], micro-vessels and vascularized tissue fabrication [33], for cell transfection strategies [34] and for cell culture of neural stem cells [35], fibroblasts and keratinocytes [36, 37].

The main advantage of plotting is, therefore, the possibility of fabricating large hydrogel constructs, capable of containing a clinically relevant amount of islets, with a porous structure that might improve oxygen and nutrient supply to the embedded cells. In this study, plotting of cell-laden hydrogels constructs is extended to large cell aggregates of $50-300 \mu \mathrm{m}$ in diameter, such as islets of Langerhans.

We hypothesized that islets embedded in a porous plotted structure could have a better glucose and insulin exchange, compared to bulk hydrogels. We show that the material choice and construct shape are of 
crucial importance in defining the viability and functionality of the embedded cells.

\section{Materials and methods}

\subsection{INS1E cell culture and islet culture}

INS1E $\beta$-cell line, derived from rat insulinoma, were kindly provided by Dr Guigas, LUMC, Leiden, The Netherlands and Dr Maechler, University Medical Center, Geneva, Switzerland. Cells were cultured in RPMI 1640 (Gibco) supplemented with 5\% (v/v) FBS (Lonza), 1\% pen/strep (Gibco), 1\% sodium pyruvate (Sigma) and 1\% HEPES $1 \mathrm{M}$ (Invitrogen). For cell expansion, $\beta$-mercaptoethanol (Invitrogen) was added fresh to the culture to a final concentration of $1 \mu \mathrm{ml}^{-1}$ medium. Medium was refreshed every 2-3 days.

Human cadaveric donor pancreata were procured via a multi-organ donation program. Isolated human islets were used in this study if they could not be used for clinical transplantation, according to the national law, and if research consent was present. Human islets were kindly provided by the LUMC Leiden and cultured in CMRL medium (Cellgro) supplemented with $10 \%$ FBS and 1\% pen/strep according to Fraga et al [38]. Mouse islets were isolated from double heterozygous crossbreed mice between $\mathrm{Tg}$ (Ins1-eGFP), Jackson Laboratory strain \#006864, and B6(CAGDsRed ${ }^{*}$ MST), Jackson Laboratory strain \#005441 and kindly provided by Hubrecht Institute Utrecht. Mouse islets were cultured in ultra-low attachment plates with RPMI 1640 (Gibco) supplemented with 10\% FBS and $1 \%$ pen/strep.

\subsection{Preparation of alginate mixtures and cell- containing bulk hydrogels}

Alginate powder (Sigma) was sterilized by $5 \mathrm{~min}$ exposure to UV light (Labino Duo spotlight) with an intensity of $45 \mathrm{~mW} \mathrm{~cm}^{-2}$ at $38 \mathrm{~cm}$ and dissolved at a $4 \% \mathrm{w} / \mathrm{v}$ concentration in PBS (PAA). Pre-crosslinked alginate was prepared by mixing a $5.3 \% \mathrm{w} / \mathrm{v}$ alginate solution with a $102 \mathrm{mM} \mathrm{CaCl}_{2}$ solution (Sigma) in HEPES $10 \mathrm{mM}$ in a $3: 1$ volume ratio, resulting in a final alginate concentration of $4 \% \mathrm{w} / \mathrm{v}$. Two syringes connected with a T-shaped connector were used to mix the calcium chloride solution with alginate and after mixing this precursor solution was used for plotting. After scaffold preparation the resulting construct was definitively crosslinked by using $102 \mathrm{mM}$ $\mathrm{CaCl}_{2}$ solution. Similarly, an alginate $4 \% /$ Matrigel $25 \% \mathrm{w} / \mathrm{v}$ mixture was also prepared, by pipetting. Additionally, alginate $4 \%$ /gelatin $5 \% \mathrm{w} / \mathrm{v}$ and alginate $4 \%$ /hyaluronic acid $0.5 \% \mathrm{w} / \mathrm{v}$ mixtures were prepared by dissolving $0.8 \mathrm{~g}$ of alginate in $20 \mathrm{ml}$ of a $5 \% \mathrm{w} / \mathrm{v}$ bovine gelatin solution (gelatin type $\mathrm{B}$, Sigma), or in $0.5 \% \mathrm{w} / \mathrm{v}$ hyaluronic acid solution (Fluka) at $37^{\circ}$. Gelatin and hyaluronic acid solution were filter sterilized using an $0.22 \mu \mathrm{m}$ filter unit (Millipore) attached to a $10 \mathrm{ml}$ syringe (Norm-Ject HSW). All the different alginate mixtures are summarized in table 1 . Ultrapure alginate was kindly provided by De Vos (UMCG Groningen) and used at a concentration of $2 \% \mathrm{w} / \mathrm{v}$ in PBS after purification according to De Vos et al [26].

Viscosity of the different alginate compositions was quantified using an Anton Paar Physica MCR 301 rheometer with flat plate geometry $(20 \mathrm{~mm}$ diameter, $1 \mathrm{~mm}$ gap). Shear rate ranged from 0.01 to $1001 \mathrm{~s}^{-1}$. Given the non-Newtonian behavior of alginate solutions, viscosity measurement at a low shear rate of 0.03 $1 \mathrm{~s}^{-1}$ was selected.

When islets or cells were added to the different gel mixtures, $10 \times 10^{6}$ cells $/ \mathrm{ml}$ were resuspended in the less viscous component of the mixture $\left(\mathrm{CaCl}_{2}\right.$, gelatin, hyaluronic acid solution or in Matrigel) to obtain a homogeneously dispersed cell suspension and mixed with a $5.3 \% \mathrm{w} / \mathrm{v}$ alginate solution, in a $1: 3$ ratio, to a final $4 \% \mathrm{w} / \mathrm{v}$ alginate concentration. Both plotted and bulk constructs $(0.3 \mathrm{ml})$ were crosslinked with a $102 \mathrm{mM} \mathrm{CaCl}_{2}$ in $10 \mathrm{mM}$ HEPES solution for $15 \mathrm{~min}$ and then washed for $5 \mathrm{~min}$ with tris buffered saline (TBS) [31]. Other crosslinking solutions used in this study were $20 \mathrm{mM} \mathrm{CaCl}_{2}$ in $10 \mathrm{mM}$ HEPES and $20 \mathrm{mM} \mathrm{BaCl}_{2}$ (Sigma) in $10 \mathrm{mM}$ HEPES to study the effect of crosslinking strength and ion on islet activity.

\subsubsection{D hydrogel plotting}

Constructs were plotted using a 3D bioplotter (SysENG, Germany). Briefly, a cell suspension in hydrogel is laden into a syringe. The hydrogel is then extruded from the syringe in a controlled layer by layer fashion by a $X Y Z$ moving arm, which deposits the material into a predefined 3D structure according to a computer aided design model (CAD-model).

Plotting settings were set accordingly to the viscosity of the material. Plotting speed ranged from 750 to $1100 \mathrm{~mm} \mathrm{~min}^{-1}$, needle diameter ranged from 0.41 to $0.2 \mathrm{~mm}$. Alginate $4 \% /$ gelatin $5 \% \mathrm{w} / \mathrm{v} 2 \times 2 \mathrm{~cm}$ construct was plotted with a $X Y$ speed of $750 \mathrm{~mm} \mathrm{~min}^{-1}$, a spindle speed of $1.75 \mathrm{~mm} \mathrm{~min}^{-1}$ and a needle diameter of $0.41 \mathrm{~mm}$ for a total of 17 layers. A $0.41 \mathrm{~mm}$ needle diameter was selected to be compatible with an islet size, which ranges between 50 and $300 \mu \mathrm{m}$. Plotting settings for the other compositions are reported in detail in table 1 . The spacing between each individual strand of the porous constructs was set on $3 \mathrm{~mm}$ to assure open pores in the constructs, whereas solid constructs were plotted with an offset of $1.16 \mathrm{~mm}$ to avoid strand superposition in following layers and create a compact structure. Control bulk samples were prepared by pipetting the same volume of hydrogel precursor on a petri dish, and they were then immediately crosslinked. 
Table 1. Parameters used for plotting different alginate mixtures, number of layers that could be plotted and viscosity values for each alginate composition.

\begin{tabular}{|c|c|c|c|c|c|c|}
\hline & Needle $\varnothing(\mathrm{mm})$ & $F_{x y}$ speed $\left(\mathrm{mm} \mathrm{min}^{-1}\right)$ & Spindle speed $\left(\mathrm{mm} \mathrm{min}^{-1}\right)$ & Layer thickness (mm) & Layer number & Viscosity $\left(\mathrm{Pa} \mathrm{s}^{-1}\right)$ \\
\hline Alginate & 0.41 & 1000 & 1.75 & 0.20 & 10 & $11.2 \pm 0.85$ \\
\hline Pre-crosslinked alginate & 0.41 & 500 & 1.75 & 0.20 & 15 & $2923.33 \pm 958.45$ \\
\hline Alginate 4\%/Gelatin 5\% & 0.41 & 1100 & 1.75 & 0.10 & 17 & $163.67 \pm 26.72$ \\
\hline Alginate $4 \% /$ Hyaluronic acid $0.5 \%$ & 0.41 & 1500 & 1.50 & 0.10 & 7 & $9.13 \pm 1.48$ \\
\hline Alginate 4\%/Matrigel 25\% & 0.41 & 1250 & 2.00 & 0.10 & 10 & $25.8 \pm 1.51$ \\
\hline
\end{tabular}




\subsection{D plotted construct characterization}

Blue colored polystyrene beads of $100 \mu \mathrm{m}$ diameter (Phosphorex) were used as a model for islets and embedded in a plotted alginate $4 \%$ /gelatin $5 \% \mathrm{w} / \mathrm{v}$ construct (referred from now on as alginate/gelatin) in a concentration of $45^{\prime} 000$ beads $/ \mathrm{ml}$. Constructs were plotted and pictures were taken with a stereomicroscope (Nikon SMZ-10 A, equipped with Qcaputre software). The bead/pore distance of circa 400 beads (20 images) was measured with Image J.

\subsection{Glucose diffusion measurement}

An $80 \mu \mathrm{l}$ bulk alginate/gelatin hydrogel was prepared as previously described and placed in the rubber insert of a custom made chamber to measure glucose diffusion through the gel. The $80 \mu \mathrm{l}$ hydrogel volume resulted in a gel thickness of $1 \mathrm{~mm}$. The device is composed of two chambers. One of the compartments has been loaded with $50 \mathrm{ml}$ of $12 \mathrm{mM}$ glucose, $1 \%$ pen/strep $102 \mathrm{mM} \mathrm{CaCl}_{2}$ in $10 \mathrm{mM}$ HEPES; the other compartment was loaded with the same solution, without glucose. Samples were taken from both compartments at defined time points and the concentration of glucose in time was measured using a VITROSS DT60 II chemistry system (Ortho-Clinical diagnostics).

The 'lag time' method was used for the calculation of glucose diffusion coefficient $\left(\mathrm{cm}^{2} \mathrm{~s}^{-1}\right)$ in alginate $4 \% /$ gelatin $5 \%(\mathrm{w} / \mathrm{v})$ gel according to the method described by Hannoun and Stephanopoulos [39]. This method is based on Fick's law of diffusion, with constant diffusion coefficient. Total glucose flux through the gel was calculated and plotted as a function of time. A constant flow/time ratio, represented by the linear part of the graph, is reached only after a certain period of time, and this period of time is referred to as the lag time. The lag time is the time a glucose molecule needs to diffuse through the whole thickness of the gel $(l)$, before the glucose flux becomes constant in time. The lag time is calculated as the intercept of the linear function on the $x$ axis an it is given by $t=l^{2} / 6 D$, where $D$ is the diffusion coefficient, $t$ the time and $l$ the thickness of the gel layer The diffusion coefficient can be then calculated as $D=l^{2} / 6 t$. The lag time corresponds to the time difference in which the diffusing molecule, glucose in this case, starts penetrating the hydrogel and the time at which the glucose flow rate into the acceptor chamber reaches a steady state [40].

\subsection{Cell viability and metabolic activity}

Cell viability was measured with a live/dead viability assay (Invitrogen) according to the provided protocol and images were taken with a fluorescence microscope (Nikon Eclipse E600). Before imaging, hydrogels were cut in half using a scalpel. The resulting slice had a thickness of about $850 \mu \mathrm{m}$, the plotted morphology was maintained and four pictures per scaffold, in a random area, were analyzed to score the percentage of live cells to total cells.

To measure cell metabolism in the three different constructs shapes, medium samples of $3 \times 10^{6}$ cells/ construct cultured in bulk, plotted porous or plotted solid hydrogels were taken every second day and glucose and lactate concentrations in the medium were measured with a VITROSS DT60 II chemistry system (Ortho-Clinical diagnostics). After every analysis, medium was refreshed for further culturing.

\subsection{Lentiviral transduction of human islets}

Islets were overnight transduced by incubating them in $3 \mathrm{ml}$ DMEM medium containing 1\% pen/strep, $10 \%$ FBS, $8 \mathrm{ng} \mathrm{mL}^{-1}$ polybrene (Sigma-Aldrich), and pRRL-CMV-GFP virus (1000 $\mathrm{ng} \mathrm{ml}^{-1}$ ). After transduction, islets were extensively washed in PBS and cultured again in RPMI supplemented with 10\% FBS and $1 \%$ pen/strep. Circa 500 of the brightest transduced islets were selected and used for plotting and for bulk hydrogel embedding.

\subsection{Islet plotting and imaging}

1000 IEQ of transduced human islets were mixed with alginate $4 \%$ / gelatin $5 \% \mathrm{w} / \mathrm{v}$ and alginate $4 \% \mathrm{w} / \mathrm{v}$. Islets were plotted according to the procedure or embedded in bulk hydrogel and imaged at day 1, 4 and 7 with a Leica TCS SP5 AOBS two-photon microscope. The microscope was equipped with a $20 \mathrm{x}$ dry objective, NA 0.40 . The laser lines used were $488 \mathrm{~nm}$ for GFP and the emission filter used was a $495-540 \mathrm{~nm}$. Mouse islets were similarly plotted and imaged using a $488 \mathrm{~nm}$ excitation line/495-540 nm emission filter for GFP and a $561 \mathrm{~nm}$ excitation line/570-620 nm filter for DsRed. Non-transduced islets were imaged in the bright field mode.

\subsection{INS1E cell sample preparation for glucose induced insulin secretion test (GIIST)}

Glucose responsiveness of INS1E cells embedded in alginate $4 \%$ /gelatin $5 \% \mathrm{w} / \mathrm{v}$ bulk hydrogel was compared to INS1E cells cultured on tissue culture plastic. $3 \times 10^{6}$ cells/sample were seeded in a T25 flask and an equal amount of cells was embedded in $0.1 \mathrm{ml}$ of bulk hydrogel. Cells were mixed with alginate $4 \%$ / gelatin $5 \% \mathrm{w} / \mathrm{v}$ solution at a density of $30 \times 10^{6}$ cells $/ \mathrm{ml}$ and crosslinked with $102 \mathrm{mM} \mathrm{CaCl}_{2}$ in $10 \mathrm{mM}$ HEPES for $15 \mathrm{~min}$. Cell laden hydrogels were also crosslinked with $20 \mathrm{mM} \mathrm{CaCl}_{2}$ in $10 \mathrm{mM}$ HEPES for 20 and $30 \mathrm{~min}$, and with $20 \mathrm{mM} \mathrm{BaCl}_{2}$ in $10 \mathrm{mM}$ HEPES for $10 \mathrm{~min}$. The previous conditions were also compared to INS1E embedded in 1\% w/v agarose (Invitrogen).

\subsection{Islet sample preparation for GIIST}

Twenty five islets per sample were embedded in $0.1 \mathrm{ml}$ of alginate $4 \%$ / gelatin $5 \% \mathrm{w} / \mathrm{v}$ and crosslinked with $102 \mathrm{mM} \mathrm{CaCl}_{2}$ in $10 \mathrm{mM} \mathrm{HEPES}$ for 5 or $15 \mathrm{~min}$, with $\mathrm{CaCl}_{2} 20 \mathrm{mM}$ in $10 \mathrm{mM}$ HEPES for $20 \mathrm{~min}$ or with 
$\mathrm{BaCl}_{2} 20 \mathrm{mM}$ in $10 \mathrm{mM}$ HEPES for $10 \mathrm{~min}$. The same number of islets were also embedded in $2 \% \mathrm{w} / \mathrm{v}$ ultrapure alginate and crosslinked for $15 \mathrm{~min}$ with $102 \mathrm{mM} \mathrm{CaCl}_{2}$ in HEPES. Free floating islets in ultralow attachment plate were used as control. After gel crosslinking, all the samples were washed with TBS and cultured in CMRL medium. At day one a GIIST was performed. After the function test, the alginate hydrogels (102 mM $\mathrm{CaCl}_{2}$ crosslinking for $15 \mathrm{~min}$ ) were solubilized by incubating them in $1 \mathrm{ml}$ of dissolving buffer containing $0.15 \mathrm{M} \mathrm{NaCI}$ (Merck), $30 \mathrm{mM}$ disodium-ethylenediamine tetra acetic acid (EDTA disodium salt) (Calbiochem) and $55 \mathrm{mM}$ sodium citrate (Sigma-Aldrich) [41] for $40 \mathrm{~min}$. Islets were retrieved from the gel and after 2 days the function test was repeated again comparing free floating untreated islets, free floating islets treated with the dissolving buffer and islets previously embedded in the gel and treated with the dissolving buffer for their retrieval.

For testing islet functionality in the plotted constructs, the plotted scaffold and the bulk samples were prepared with circa 125 islets/sample and crosslinked with a $102 \mathrm{mM} \mathrm{CaCl}_{2}$ solution in $10 \mathrm{mM}$ HEPES for $15 \mathrm{~min}$, followed by a wash with TBS. Both bulk and plotted constructs final volume was $0.3 \mu \mathrm{l}$. Insulin secretion test was performed as following and compared with the same amount of free floating islets.

\subsection{Islet and INS1E GIIST}

Islet functionality was tested as reported elsewhere [18]. The GIIST protocol was slightly modified for testing INS1E functionality. Briefly, islets were preincubated in Krebs-Ringer low glucose buffer (1.67 $\mathrm{mM}$ glucose) for $1.5 \mathrm{~h}$ while INS1E samples were incubated for two hours in RPMI medium without glucose (Invitrogen). Samples were then exposed for $1.5 \mathrm{~h}$ in case of islets, or for $45 \mathrm{~min}$ in case of INS1E, to a low glucose Krebs-Ringer buffer containing $1.67 \mathrm{mM}$ glucose. Subsequently, samples were incubated for an equal period of time respectively in high glucose medium (16.7 mM glucose) followed by a last incubation in low glucose medium $(1.67 \mathrm{mM})$. Samples were collected at the end of each incubation step for further analysis. Released insulin was quantified by using an ELISA kit (Mercodia). Results were presented as low-high-low profiles, both as actual amount of insulin secreted $\left(\mathrm{mUl}^{-1}\right)$ and as stimulation index, which is the ratio of insulin secretion between the high and low glucose condition.

\subsection{Statistical analysis}

Experiments were performed in triplicate. All the quantitative data are expressed as mean \pm standard deviation. Data were analyzed using a one-way ANOVA, followed by Bonferroni post-hoc test. The analysis was performed using IBM SPSS statistic 20 software. Significant difference between groups is indicated with ${ }^{\star}(p \leqslant 0.05)$.

\subsection{3. implantation and in vivo imaging}

Circa 500 of the brightest transduced islets were plotted in the scaffold following the usual procedure. A $1 \mathrm{~cm}$ circular section of the plotted scaffold was punched out and glued on one side of a pre-sterilized abdominal imaging window by using $\mathrm{H}$-butyl-cyanoacrylate glue. Two other equal sections of the same scaffold were used as a subcutaneously implanted control and as an in vitro control, respectively. The window was implanted on the back of NSG mice (Jackson Laboratory), the second part of the scaffold was implanted subcutaneously as a control.

The islet graft was monitored at day 1, 4 and 7 (figure 8). Intravital imaging was performed by placing the mouse in a custom designed imaging box. The imaging window was fixed in a ring-opening on the bottom part of the box. The box was also equipped with a nose cone for anesthesia, air ventilation, and a MouseOx system (Starr Lifescience Corp) to monitor vital signs. The imaging was performed keeping the mouse at a controlled temperature of $32^{\circ} \mathrm{C}$. A Leica TCS SP 5 confocal microscope was used and equipped with a 20x dry, NA0.40 objective, a $488 \mathrm{~nm}$ laser line for GFP and a 495-540 nm emission filter. After seven days the mouse was sacrificed with isoflurane anesthesia and the graft was explanted and processed for histology.

Explants were fixed with $4 \% \mathrm{w} / \mathrm{v}$ paraformaldehyde, dehydrated, and embedded in paraffin. Sections 4-8 $\mu \mathrm{m}$ thick were cut and stained with hematoxylin and eosin. Alternatively, immunostainings for insulin (Dako; 1:200) and glucagon (Vector Laboratories; $1: 100)$ were performed. Images were acquired on a Leica TCS SPE with a 20x oil-immersion objective.

\section{Results}

\subsection{Scaffold fabrication by $3 \mathrm{D}$ plotting and characterization}

Different alginate-extracellular matrix components blends have been successfully plotted. As shown in table 1, only some of these blends had sufficient mechanical properties to allow plotting and handling of the final construct. The plotting speed and spindle speed were adjusted according to the viscosity of the material, being slower for highly viscous materials (table 1). Among all the other composition tested, alginate $4 \%$ /gelatin $5 \%(\mathrm{w} / \mathrm{v})$ composition was found to be the most suitable for scaffold plotting, because of the high viscosity of the blend compared to all the other materials tested. This assured better plotting performances in terms of handling and stability of multilayered cell-laden constructs (table 1).

This mixture was selected for future experimentation. Handling and plotting of the alginate/gelatin 


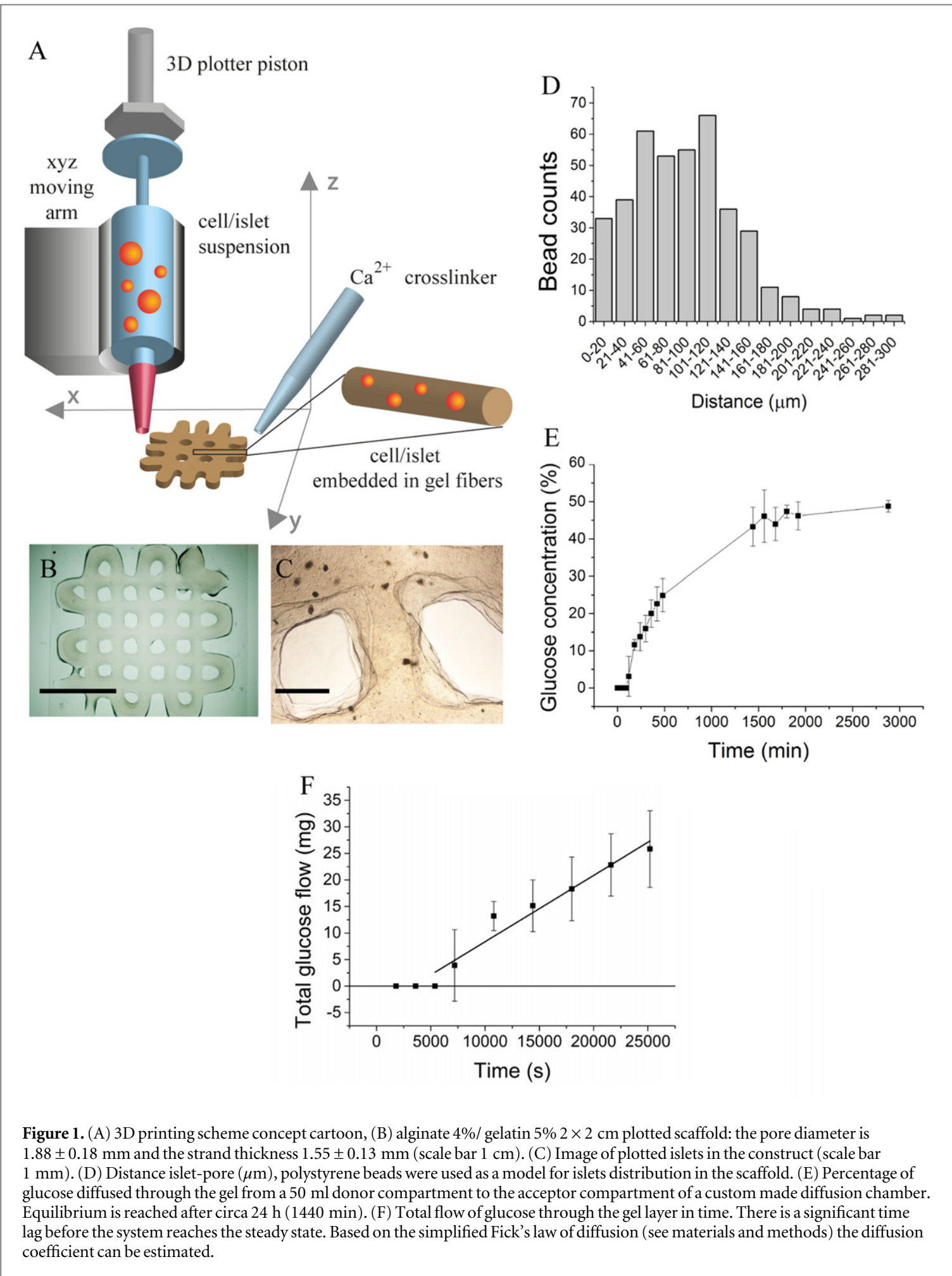

mixture was further improved by the partial gelation of gelatin at room temperature, compared to the lower viscosity of its initial state $\left(37^{\circ} \mathrm{C}\right.$, required for solution preparation) because of the gelation of the gelatin component at room temperature, which increased the viscosity of the mixture during plotting.

Alginate/gelatin blend allowed plotting up to 17 layers, resulting in scaffolds with open pores in the $X$ $Y$ direction (table 1). The number of layers defines how many times the strand deposition process was repeated on top of each other according to the template (CAD model) to achieve the final construct. In a $2 \times 2 \mathrm{~cm}$ scaffold, the pore diameter was $1.88 \pm 0.18 \mathrm{~mm}$ and the strand thickness of the construct $1.55 \pm 0.13 \mathrm{~mm}$ (figure 1 ). The diameter of the needle used was $0.41 \mathrm{~mm}$, resulting in a final scaffold 3.7 times thicker because of the superpositioning of 17 layers on top of each other, which showed a partial collapse of the viscous hydrogel precursor before crosslinking. Similarly, the spacing between strands 
decreased during plotting to $0.5 \mathrm{~mm}$ instead of the initial $3 \mathrm{~mm}$ programmed into the CAD model. In contrast to conventional thermoplastic polymers extrusion, the hydrogel construct had no pores along the cross-section ( $z$ direction). This fact is explained by the low viscosity of the hydrogel precursor compared to molten polymers and also by the fact that the crosslinking procedure was performed after the plotting of the last layer.

Polystyrene beads of $100 \mu \mathrm{m}$ in diameter were used as a model for islets of Langerhans to study their distribution in the plotted construct. After plotting, the distance between each bead and the closest pore of the scaffold was measured (figure 1(E)). Beads were homogeneously distributed in the scaffold, in close proximity to the pores. The layer of gel surrounding them had a reduced thickness compared to conventional bulk structures. The great majority of the beads were at less than $200 \mu \mathrm{m}$ from the closest pore (figure 1(E)), which was considered still close enough to the external environment to allow oxygen diffusion to the islets [42].

\subsection{Glucose diffusion measurements}

In order to determine mass transport in this material, a two compartment glucose diffusion assay was performed. Scaffolds were placed in between a compartment containing $12 \mathrm{mM}$ glucose and a compartment containing no glucose. Glucose diffusion through the gel was found to be limited by the alginate/gelatin mesh. Only after $24 \mathrm{~h}$ the glucose concentration in both $50 \mathrm{ml}$ compartments of the chamber reached the equilibrium, accounting for a delay in glucose diffusion through the gel. The graph in figure $1(\mathrm{~F})$ shows the total flow of glucose in function of time through the gel layer. The graph shows a significant lag time before the glucose flow to time ratio becomes constant (steady state condition). This lag time allows for the calculation of the diffusion coefficient according to $t=l^{2} / 6 D$, as explained in the materials and methods. The resulting glucose diffusion coefficient in alginate $4 \%$ /gelatin $5 \%$ $(\mathrm{w} / \mathrm{v})$ gels was estimated to be $D=1.13 \times 10^{-6} \mathrm{~cm}^{2} \mathrm{~s}^{-1}$. In literature, the diffusion coefficient of glucose in water and in a $4 \%$ alginate solution has been reported to be $6.7 \times 10^{-6} \mathrm{~cm}^{2} \mathrm{~s}^{-1}$ [43] and $5 \times 10^{-6} \mathrm{~cm}^{2} \mathrm{~s}^{-1}$, respectively [39]. Both coefficients are significantly bigger compared to glucose diffusion values in our system.

\subsection{INS1E viability screening in bulk materials}

INS1E insulinoma cells were used as a model for islets of Langerhans and encapsulated into the different alginate-ECM blends to study the effect of hydrogel composition on cell viability over 21 days of culture (figure 2 and supporting table 1). INS1E viability in alginate $4 \% \mathrm{w} / \mathrm{v}$ was suboptimal, with a mean value of
$80 \%$ of viable cells $24 \mathrm{~h}$ after embedding. Viability dropped to $50 \%$ after 3 days of culturing.

In order to further improve hydrogel biocompatibility and cell viability, alginate $4 \%(\mathrm{w} / \mathrm{v})$ was also mixed with other components such as $5 \%(\mathrm{w} / \mathrm{v})$ gelatin, $0.5 \%(\mathrm{w} / \mathrm{v})$ hyaluronic acid or Matrigel 25\% (w/ v). INS1E cells embedded in alginate $4 \% /$ gelatin $5 \%$ $(\mathrm{w} / \mathrm{v})$ performed the best in terms of cells viability, having a 95\% viable cells up to 21 days of culture. Cell viability in alginate $4 \%$ / hyaluronic acid $0.5 \%(\mathrm{w} / \mathrm{v})$ and alginate $4 \% /$ Matrigel $25 \%(\mathrm{w} / \mathrm{v})$ also showed improved cell viability, compared to alginate $4 \%$ only. However, the handling properties of the alginate/hyaluronic acid and alginate/Matrigel mixtures were less favorable than alginate/gelatin. Constructs made with these mixtures collapsed easily, were less stiff, and the plotting performances were less consistent to the CAD-model.

\subsection{Construct shape influence on cell viability and metabolic activity}

INS1E viability and metabolic activity were not influenced by the shape of the alginate/gelatin construct in which the cells were embedded (figure 3). INS1E cells were embedded in bulk constructs, plotted porous structures and plotted solid hydrogel scaffolds. The volume $(0.3 \mathrm{ml})$ and the cell concentration $\left(10 \times 10^{6}\right.$ cells $\left./ \mathrm{ml}\right)$ were kept constant to avoid differences in cell density in the three constructs shapes. Cell viability was assessed by live/dead assay and no difference was observed among the three different construct shapes analyzed (figure $3(\mathrm{~A})$ ). The same result was also obtained by analyzing the metabolic activity of the cells. The quantification of glucose and lactate concentrations in the medium resulted in no differences among the three constructs, but in an overall low metabolic activity, suggesting that embedded cells were alive but not functional in the gel (figures 3(B) and (C)), in line with results previously reported by other authors [44].

\subsection{Responsiveness of hydrogel embedded INS1E cells}

In all the conditions tested, INS1E insulin secretion was drastically reduced or totally absent in response to high glucose conditions, when cells were embedded in hydrogel constructs (figure 4). To detect a functional profile, the insulin secreted in the three low-high-low glucose conditions needs to be compared. The only condition in which a functional (low-high-low) insulin profile in response to the correspondent glucose stimulation was detected, are INS1E seeded on tissue culture plastic. In all the hydrogel compositions, no functional response was seen. Irrespectively of the type of hydrogel or the crosslinking conditions $\left(\mathrm{Ca}^{2+}\right.$ versus $\left.\mathrm{Ba}^{2+}\right)$, cells showed limited responsiveness to glucose stimuli. As reported in literature, calcium ion gradients over the 
A

B

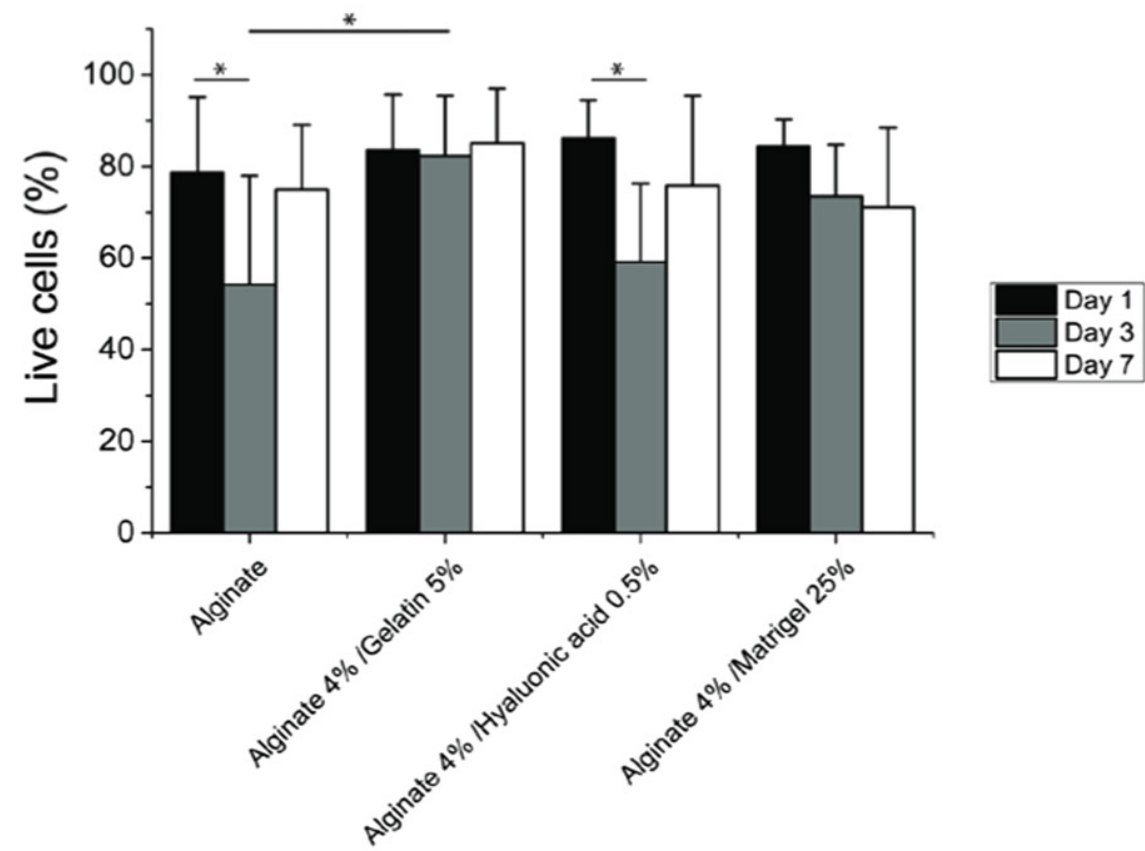

Alginate $4 \%$

Day 1

Day 3

Day 7

\section{Alginate 4\% / Gelatin 5\%}
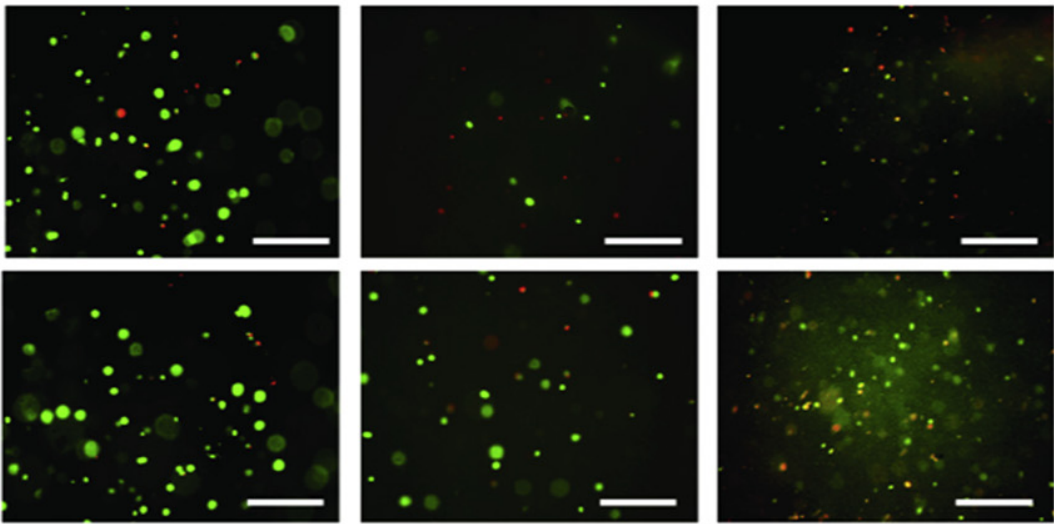

\section{Alginate 4\% / Hyaluronic acid 0,5\%}
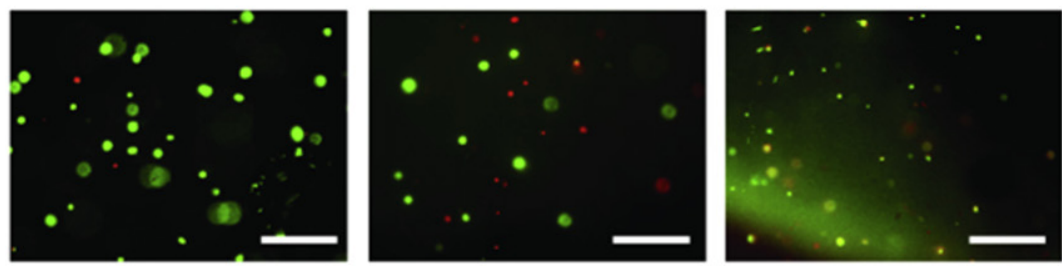

\section{Alginate 4\% / Matrigel 25\%}
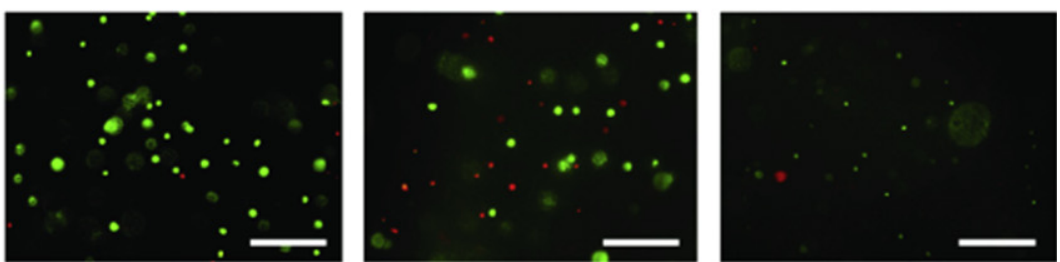

Figure 2. (A) Viability of encapsulated INS1E cells in $4 \% \mathrm{w} / \mathrm{v}$ alginate gel, alginate $4 \% \mathrm{w} / \mathrm{v} / \mathrm{gelatin} 5 \% \mathrm{w} / \mathrm{v}$, alginate $4 \% \mathrm{w} / \mathrm{v} / \mathrm{hyaluronic}$ acid $0.5 \% \mathrm{w} / \mathrm{v}$, and alginate $4 \% \mathrm{w} / \mathrm{v} /$ Matrigel $25 \% \mathrm{w} / \mathrm{v}$. (B) Live/dead pictures of INS1E cells in the different alginate compositions at days 1,3 and 7 (scale bar $200 \mu \mathrm{m}$ ).

cytoplasmic membrane are involved in regulating insulin secretion mechanism. In our experiment, the loss of functionality was independent on the type or on the concentration of the divalent cation used for crosslinking and was also observed when a non-ionic gel, as agarose, was used for embedding. For this reason, we exclude that interfering with $\mathrm{Ca}^{2+}$ equilibrium during the crosslinking procedure could be responsible for the loss of insulin secretion $[45,46]$. Once the influence of the crossliner ion was excluded, nutrient diffusion limitations, as discussed in paragraph 3.2 are considered the major reason to explain 


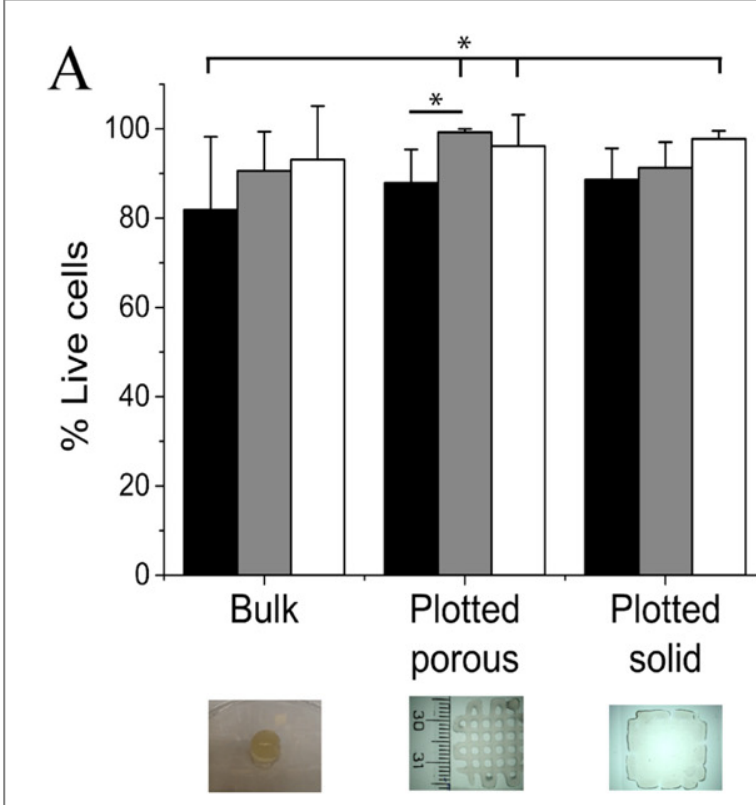

$\mathrm{D}$

Bulk

Plotted porous

Plotted solid
Day 1
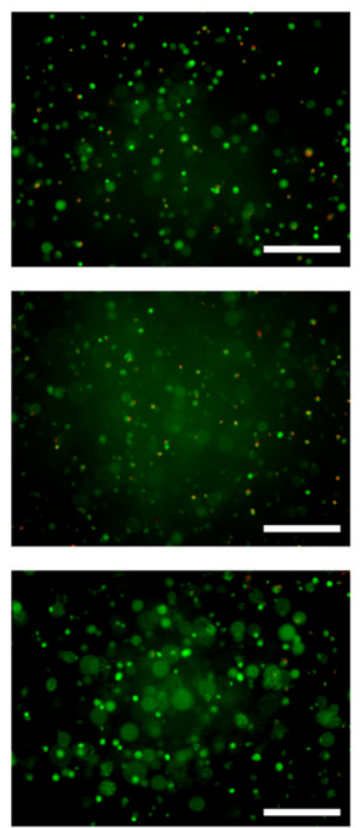
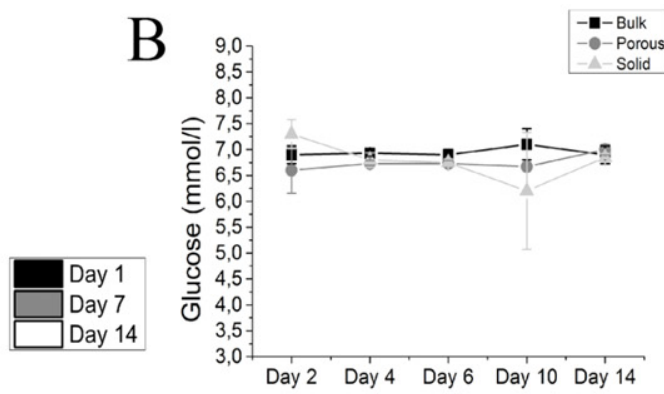

$\mathrm{C}$

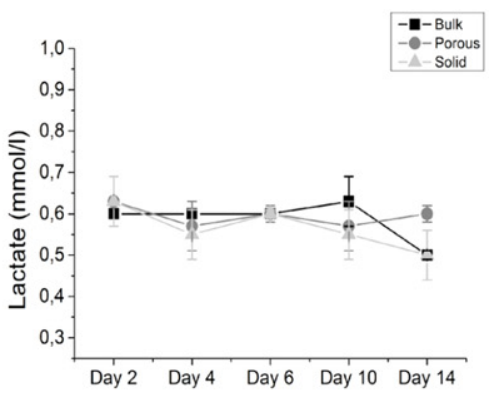

Day 7

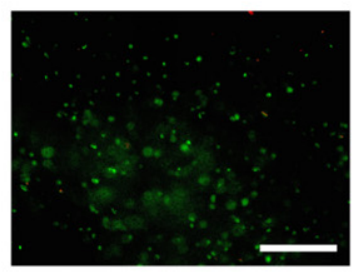

Day 14
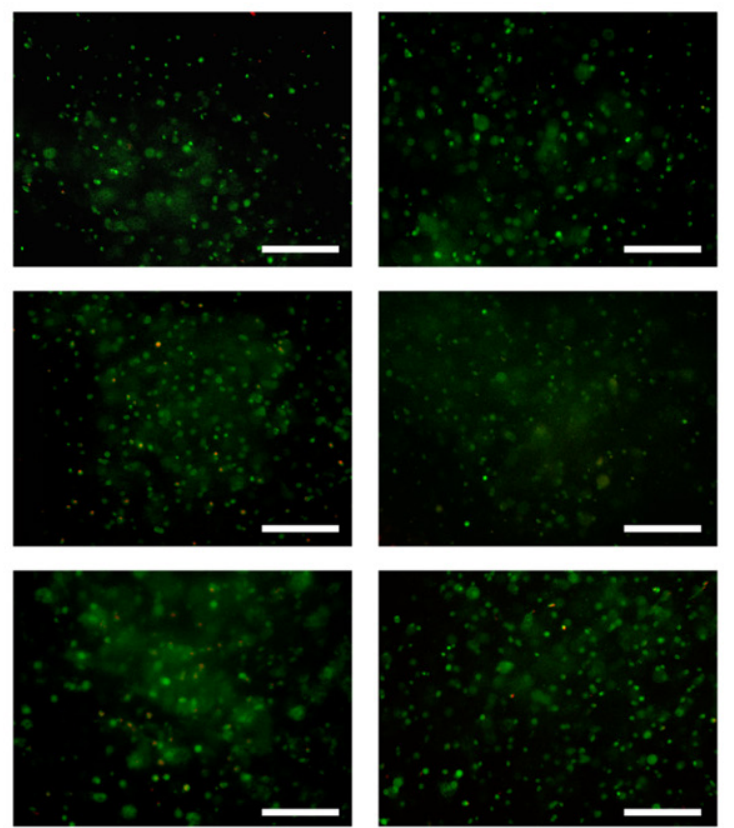

Figure 3. (A) INS1E viability in bulk constructs, plotted porous and plotted solid constructs. (B) and (C) metabolic activity of INS1E cells embedded in constructs with different geometries measured as glucose (B) and lactate (C) concentrations in the culture medium. Viability, glucose consumption and lactate production are not influenced by the plotting process or construct shape. (D) Live/dead images of the INS1E cells in the different constructs at day 1, day 7 and day 14 (scale bar $200 \mu \mathrm{m}$ ).

the loss of functionality when INS1E cells are embedded in bulk hydrogels.

\subsection{Islet transduction, embedding and functionality in the construct}

Human islets were plotted in the construct and their morphology, aggregation, viability and response to glucose challenges were analyzed and compared with bulk constructs. Before plotting, viral transduction was used to induce stable expression of GFP in the islets and allow direct visualization in the plotted construct in vitro as well as in vivo with intra-vital imaging techniques.

GFP transduced human islets plotted in the alginate/ gelatin constructs showed comparable morphology and GFP expression as the islets embedded in the same alginate/gelatin composition in bulk form, in $4 \% \mathrm{w} / \mathrm{v}$ alginate only, and in ultrapurified alginate [24-26, 47]. Ultrapure alginate was used to compare islet morphology in the new alginate/gelatin mixture to an already used material in the islets encapsulation field (figure 5).

The embedding and the plotting procedure did not induce any change in cell morphology. Islets were 


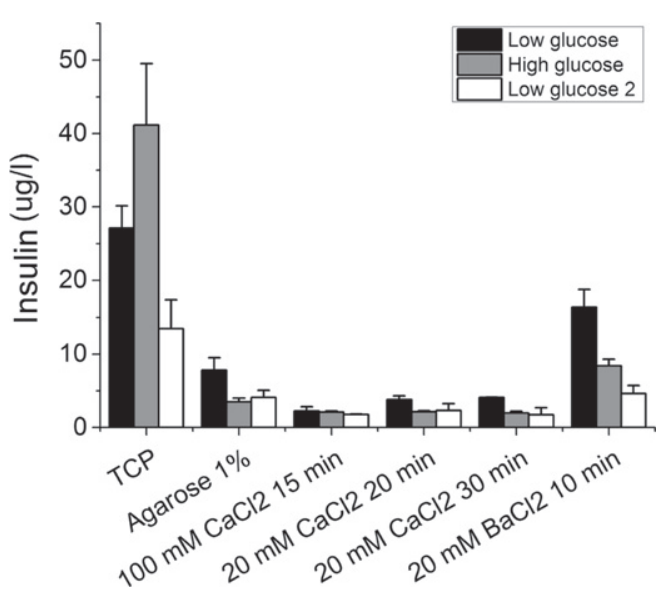

Figure 4. INS1E cells functional response in glucose induced insulin secretion test. Adherent INS1E cells on TCP have been compared to INS1E embedded in bulk agarose gel $1 \% \mathrm{w} / \mathrm{v}$, bulk alginate $4 \% \mathrm{w} / \mathrm{v} /$ gelatin $5 \% \mathrm{w} / \mathrm{v}$ crosslinked with $102 \mathrm{mM} \mathrm{CaCl}_{2}$ for $15 \mathrm{~min}$ (same crosslinking condition used for plotting) alginate/gelatin crosslinked with $20 \mathrm{mM} \mathrm{BaCl}_{2}$ for $10 \mathrm{~min}$, or with $20 \mathrm{mM} \mathrm{CaCl}_{2}$ for 20 or $30 \mathrm{~min}$. In none of the hydrogel composition analyzed, INS1E cells showed a functional response.

still round shaped and the shear stress experienced during plotting did not cause islets to disaggregate or decrease in viability. According to the morphological analysis of the embedded islets, the presence of gelatin in the hydrogel mixture did not induce islet spreading or cell adhesion. Hydrogel embedding also prevented aggregation of individual islets (figure 5 and supporting figure 2).

The native morphology of the islets was retained after plotting of murine islets (supporting figure 1). These islets were isolated from double heterozygous crossbreed mice $\mathrm{Tg}$ (Ins1-eGFP) and B6(CAGDsRed $\left.^{\star} \mathrm{MST}\right)$. In this mouse strain, all cell types are characterized by the expression of DsRed protein under the control of the ubiquitous chicken $\beta$-actin promotor. Insulin production by $\beta$-cells within the plotted islets is visualized by the specific expression of GFP, under the control of the mouse insulin promotor. The GFP signal in $\beta$-cells is much stronger than DsRed, allowing for the visualization of the insulin producing $\beta$-cells by the green GFP signal.

Islet functionality in plotted constructs was compared to islets in bulk hydrogels and to free floating islets. Islets are regarded as functional when their stimulation index is higher than 2 [61]. As shown in figure 6(A), islets in bulk hydrogels lose their functionality already after one day, being not responsive to glucose stimuli. In figure 6(B) one can see that the normal low-high-low insulin response to glucose is still present in the plotted construct while it is not visible anymore in the bulk construct. The diffusion of oxygen and insulin is slightly improved in the plotted construct compared to the bulk construct. Functionality in both bulk and plotted constructs is lost after seven days in culture. Interestingly, the reduction in the functional response of plotted islets was not caused by a reduced insulin secretion in high glucose, since this was comparable to the response of the control islets, but was due to an increased insulin secretion in low glucose condition, as shown in (figure 6(B)).

Insulin secretion is dependent on the extracellular calcium concentration [44, 45]. In an ionic crosslinked hydrogel such as alginate, the extracellular environment is rich in calcium and this fact could interfere with insulin secretion mechanism and explain the apparent loss of functionality of islets when embedded in the gel. To further investigate if islet loss of functionality is related to the divalent ion used for crosslinking, islets were embedded in different hydrogels, using different crosslinking conditions (figure $7(\mathrm{~A})$ ). Irrespectively of the crosslinking ion used (calcium or barium), or the crosslinking time used, for gelation, none of the conditions were able to sustain islet functionality. Islets in ultrapure alginate, that is often used for islet encapsulation [24-26, 47], were crosslinked under the same conditions used for plotting. Also in this case, islets were not responsive to glucose stimulation (characterized by a stimulation index lower than 1).

Since the crosslinking ion appeared not to be the limiting factor for reestablishing islet functionality, we showed that the loss of functionality of embedded islets is caused by a decreased glucose diffusion through the gel. In fact, the glucose diffusion coefficient in these gels $\left(1.13 \times 10^{-6} \mathrm{~cm}^{2} \mathrm{~s}^{-1}\right)$ has been calculated to be significantly smaller than glucose diffusion in water, or in a $4 \%$ alginate solution $\left(6.7 \times 10^{-6} \mathrm{~cm}^{2} \mathrm{~s}^{-1}\right.$ [43] and $5 \times 10^{-6} \mathrm{~cm}^{2} \mathrm{~s}^{-1}$ [39] respectively). If this hypothesis would be correct, the inhibition of islet response to glucose challenge should be transient and the islets should recover after retrieval from the gel. To further prove this point, embedded islets were retrieved from the gel and their functionality tested again 2 days after retrieval. As shown in figure $7(B)$, islets functionality was fully restored when retrieved from the hydrogel, statistical test was performed and no significant difference was found among the stimulation indexes of the three conditions This finding confirmed that islets remained viable in a plotted hydrogel despite losing glucose responsiveness. The lack of such responsiveness was likely due to limitations in glucose and nutrient diffusion.

\subsection{Intravital imaging results}

The alginate/gelatin $(4 \% / 5 \% \mathrm{w} / \mathrm{v})$ plotted hydrogel scaffolds containing islets were mounted on the imaging window and transplanted subcutaneously in nude mice. A schematic drawing can be seen in figure 8 . With this in vivo imaging technique, we were able to non-invasively image the islets in the hydrogel construct up to 7 days after transplantation. This imaging method allowed us to longitudinally monitor a specific islet in consecutive imaging sessions. We 


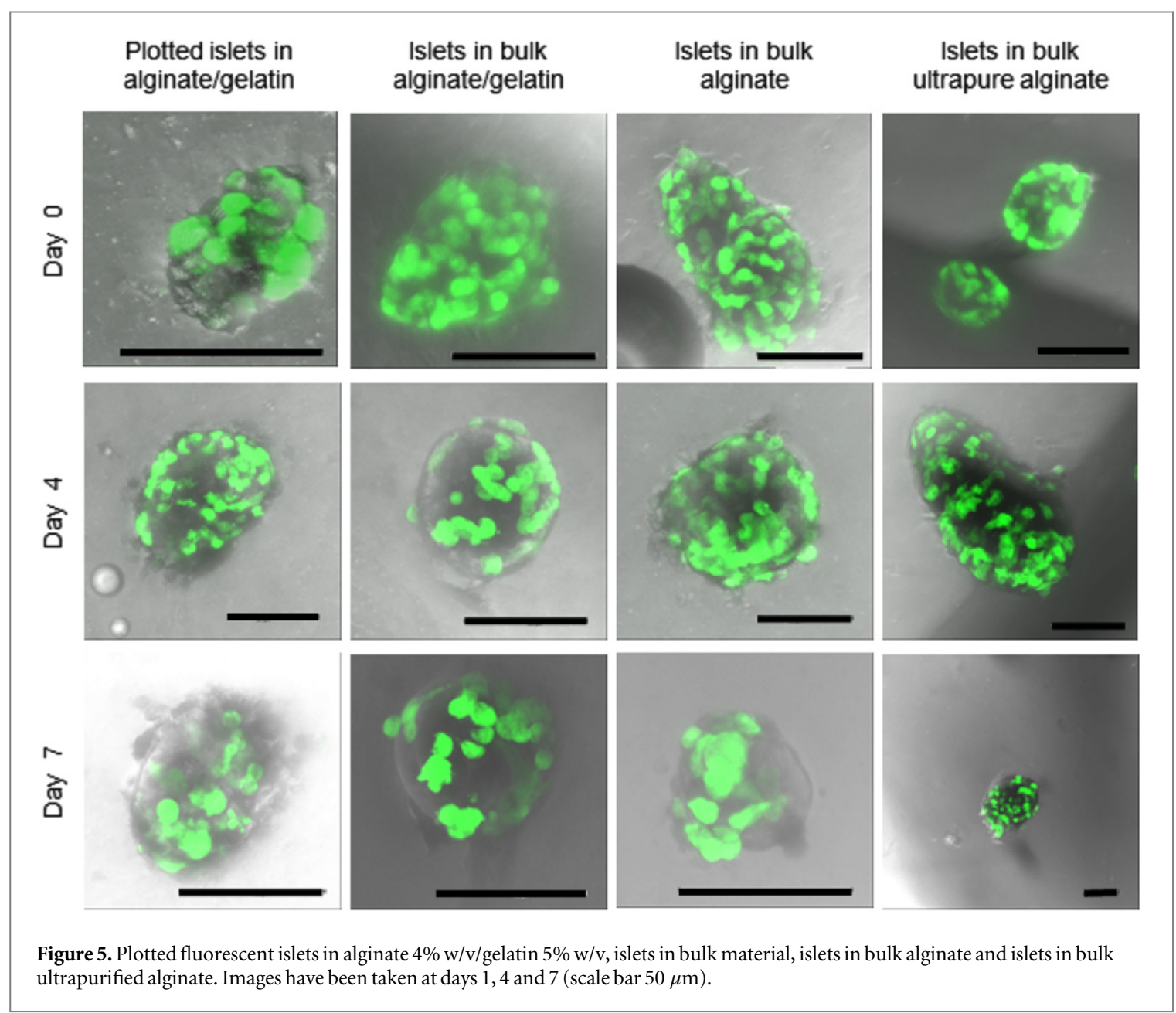

were able to detect GFP expression and image the islets in the construct at different time points (figure $8(G)$ ), where single cells within an islet are clearly visible.

At subsequent time points, islets remained visible in the construct and the same islet could be easily traced, although appearance of GFP expression changed and single cells were not as clearly visible as before. This observation can be seen in figure $8(\mathrm{G})$ by a more speckled appearance as the fluorescent signal of the cells decreased over time. This fact correlates with the diminished metabolic activity and functionality already demonstrated in the in vitro experiments. The decreased GFP signal and metabolic activity at day 4 and 7 after transplantation can be again correlated with the fact that nutrient and oxygen diffusion in the construct are limited to the lower layers of the construct, which are in direct contact with the surrounding tissue and blood vessels. The diffusion in the upper layers of the construct is restricted by the presence of the imaging window. Moreover, the intravital technique is limited to $450 \mu \mathrm{m}$ imaging depth, which allows only for the upper layers of the scaffolds to be studied. These layers are more affected by a lack of nutrients diffusion from the underlying tissues. This hypothesis was confirmed by the fact that islets in the in vitro control were still bright fluorescent up to day 7 , with no sign of cell death or disaggregation. At day 7 both the mice with a subcutaneous transplant and the mice with window implants were terminated and the alginate/gelatin scaffolds were explanted and processed for histology. Hematoxylin and eosin staining confirmed the presence of islets in the scaffold, which showed no sign of apoptotic nuclei, but no insulin or glucagon was detected by immunostaining (figure 9(D)) which might indicate a reduced metabolism due to the embedding in hydrogel and lack of sufficient nutrient supply.

\section{Discussion}

3D bioplotting is a well described technique in the field of tissue engineering, mostly applied for the extrusion of thermoplastic polymers, to create custom engineered scaffolds for the regeneration of bone and cartilage $[48,49]$. Printing allows tailoring of shape, porosity and mechanical properties: these parameters can be finely tuned in order to steer cells response to match the properties of the specific tissue to be regenerated. The only application of printing in pancreas tissue engineering is reported in a paper of Daoud et al [15], with islets being seeded in a printed poly (DL-lactide-co-glycolide) construct, a material 

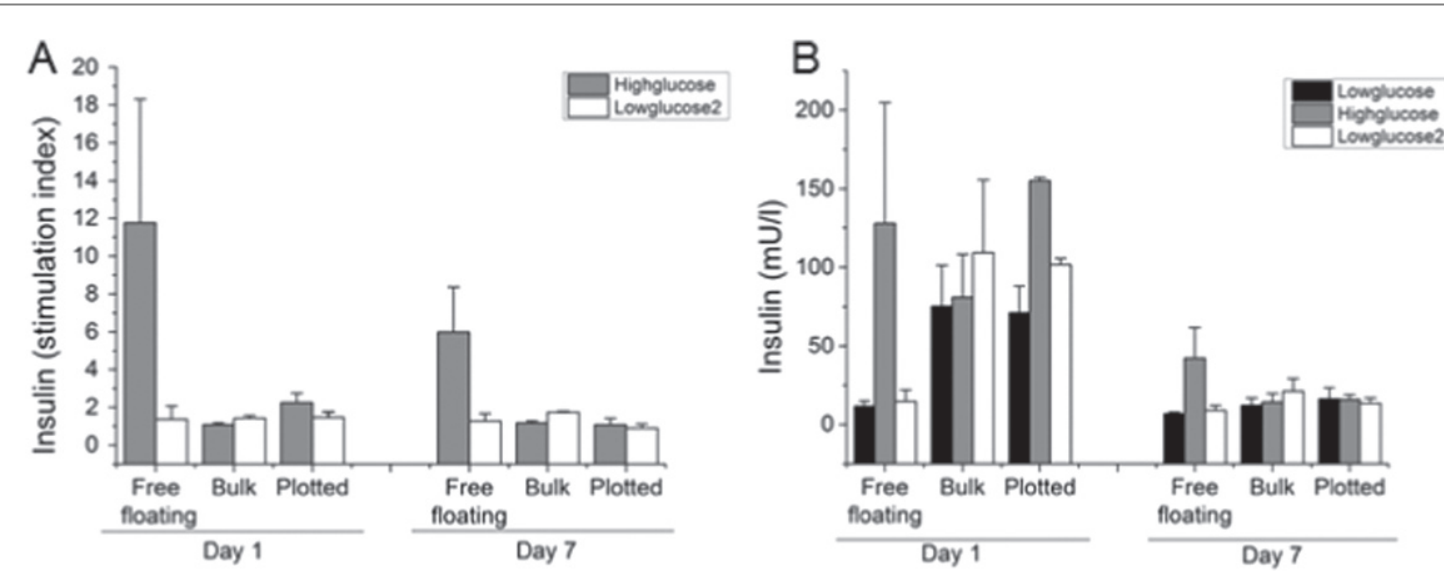

Figure 6. Glucose induced insulin secretion test on free floating islets, islets embedded in bulk hydrogel and islets in plotted constructs. At day 1, islets are functional in the plotted constructs but not in the bulk hydrogel. (A) Stimulation index normalized to insulin secreted in low glucose $1,(\mathrm{~B})$ actual values of secreted insulin $\left(\mathrm{mU} \mathrm{l}^{-1}\right)$. Islets are considered functional if the stimulation index in high glucose condition is higher than 2 [61].
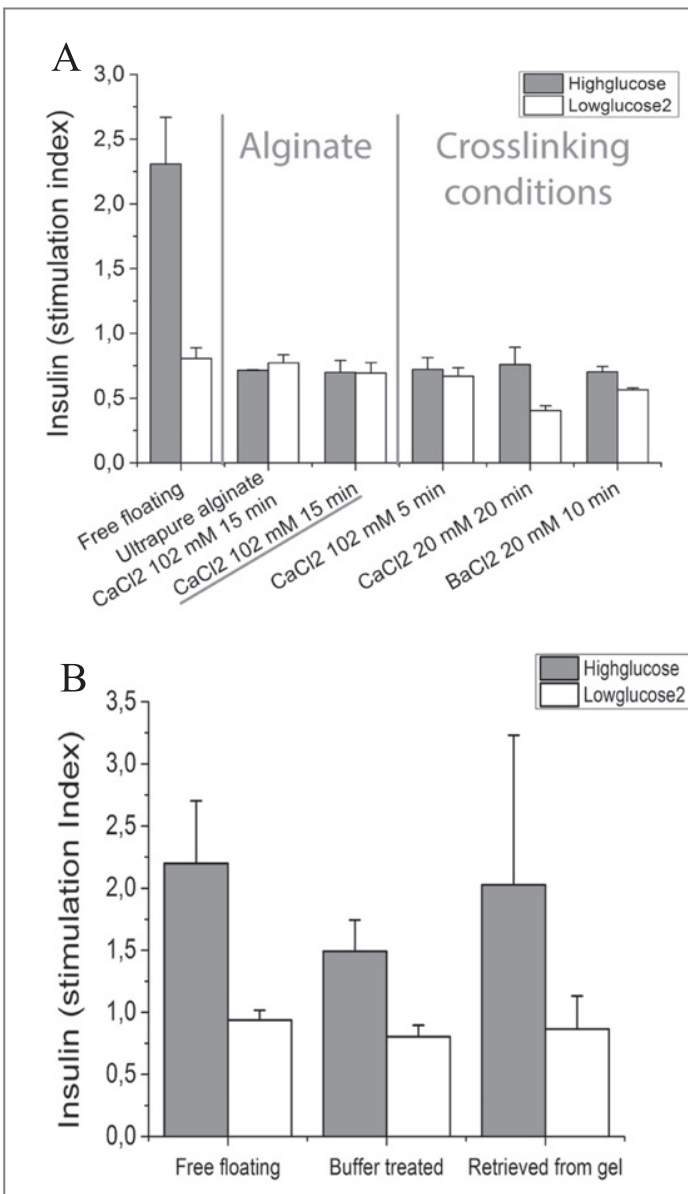

Figure 7. (A) Function test on islets cultured in different hydrogels with various crosslinking conditions. Islets have been embedded in alginate $4 \%$ /gelatin $5 \%$ or ultrapure alginate and crosslinked with $\mathrm{CaCl}_{2} 102 \mathrm{mM}$ for 5 and $15 \mathrm{~min}$, with $\mathrm{CaCl}_{2} 20 \mathrm{mM}$ for $20 \mathrm{~min}$ and with $\mathrm{BaCl}_{2}$ for $10 \mathrm{~min}$. None of the conditions tested were functional. (B) Alginate/gelatin gel crosslinked with $102 \mathrm{mM} \mathrm{CaCl}_{2}$ for $15 \mathrm{~min}$ was dissolved and islets were retrieved from the gel. Functionality was tested and compared to free floating islets and free floating islets treated with buffer. After retrieval from the gel, functionality was restored. Statistical test was performed and no significant difference was found among the stimulation indexes of the three conditions. whose mechanical properties are not comparable with those of the soft tissues in pancreas.

Combining hydrogels with the 3D bioplotting for the regeneration of soft tissues and in particular for the encapsulation of islets of Langerhans should result in a clinically relevant size construct for islet delivery. This construct will provide a protective environment for the embedded tissue, with mechanical properties better mimicking those of soft tissues, if compared to solid thermoplastic materials. In contrast to conventional embedding in bulk hydrogels, a plotted structure can increase the available surface area for nutrients and catabolites exchange, avoiding the formation of a necrotic core which can affect bulk hydrogels. This would ultimately result in the possibility of up-scaling the construct to a size that can contain a clinically relevant amount of islets.

This study demonstrates that the plotting of large cell aggregates of 50-300 $\mu \mathrm{m}$ like islets of Langerhans in a hydrogel is feasible, without compromising islet viability, morphology and aggregation.

Material selection was performed using the model cell line INS1E and high viability values were observed for INS1E and islets in the alginate/gelatin composition, but the metabolic activity of cells embedded in the hydrogel is reduced and these findings are in line with what has been also reported by other authors $[44,50,51]$. Our data suggest that islet plotting per se is not causing the impairment in functionality, but it is caused instead by impaired nutrient diffusion in such a viscous hydrogel precursor. This loss of metabolic activity cannot be rescued only by improving nutrient diffusion by means of a macro-porous structure.

Opposite results in terms of metabolic activity were reported for human mesenchymal stem cells (MSCs) encapsulated in similarly plotted constructs [31]. In this case, embedding the cells in the porous plotted scaffold had a beneficial effect on their viability compared with solid or bulk constructs [31]. 

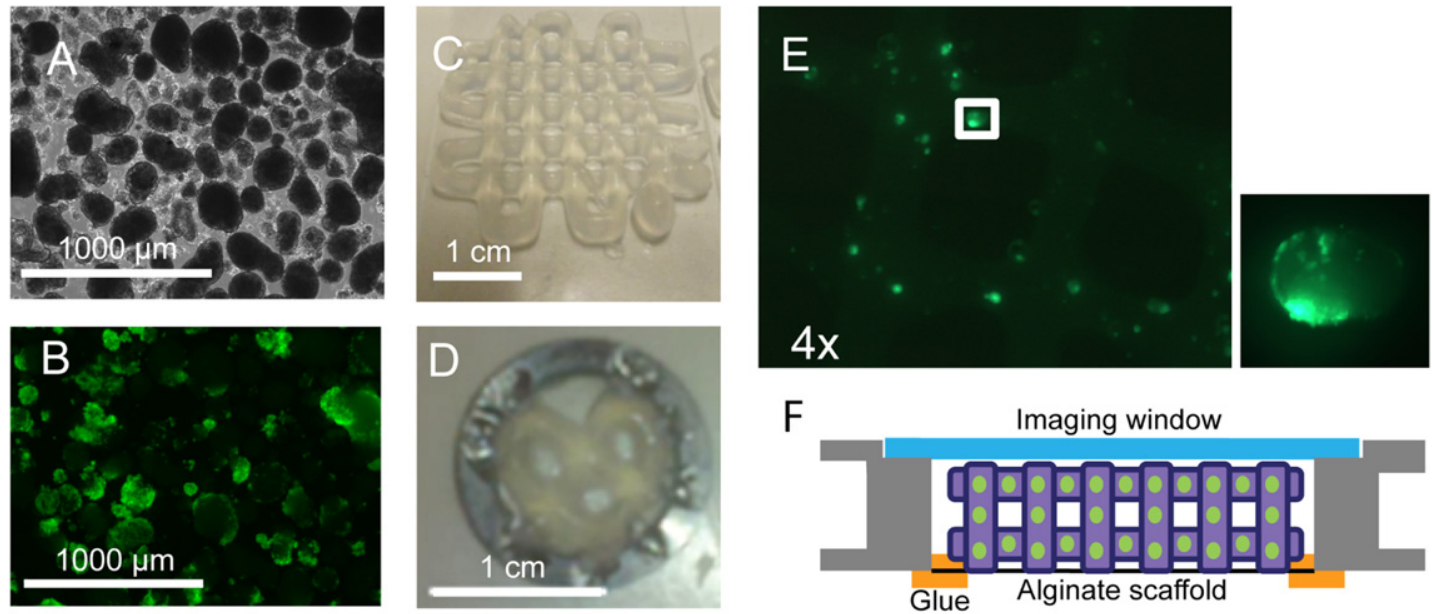

$\mathrm{F}$
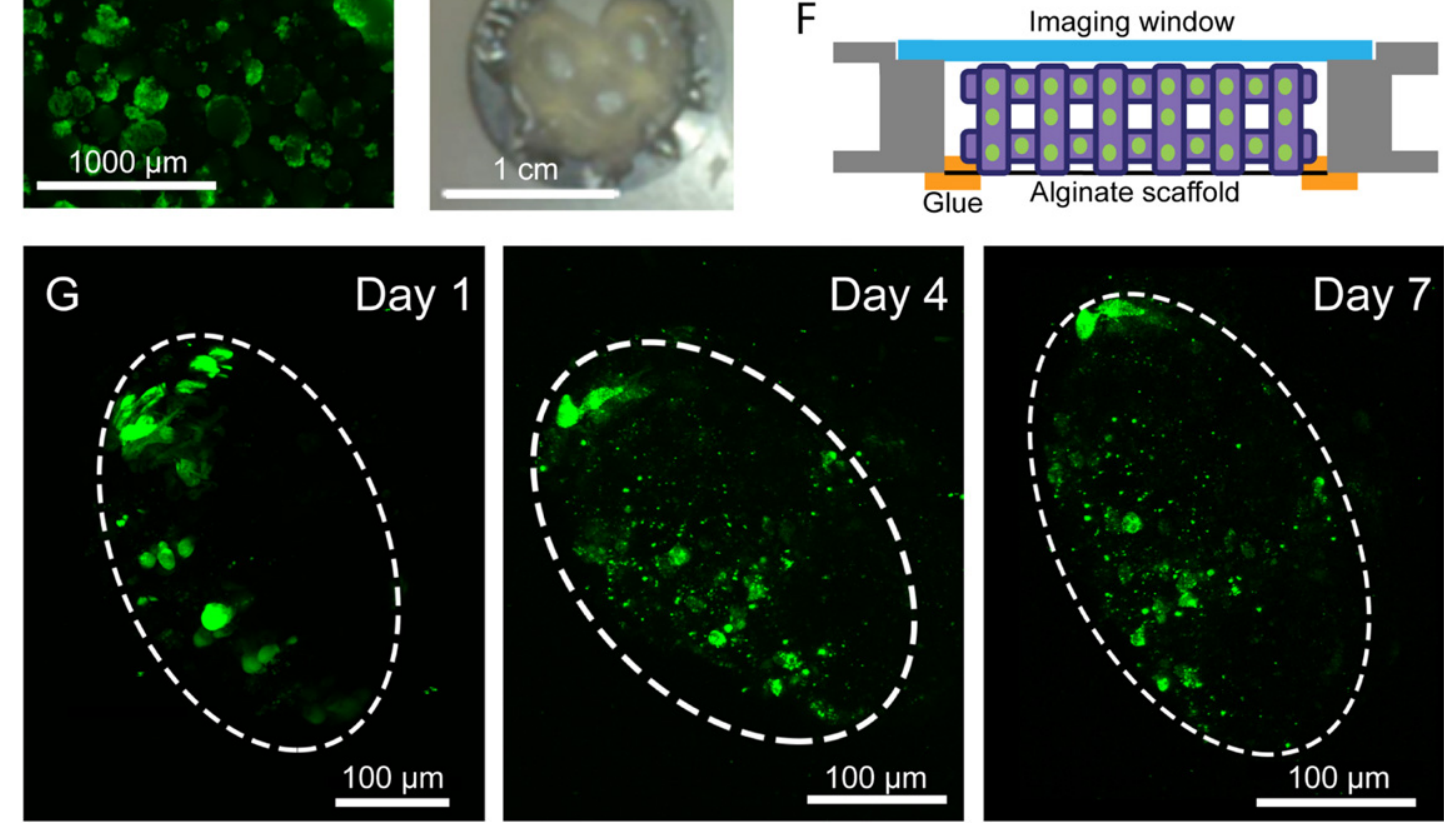

Figure 8. Human islets (A) were transduced with CMV-GFP virus, handpicked (B), and plotted into a $2 \times 2$ alginate construct (C). A $1 \mathrm{~cm}$ circular sample was glued to the abdominal imaging window, as shown in (D) and schematically depicted in (F). Figure (E) shows GFP transduced islets in a plotted construct. The same islets could be imaged at days 1, 4 and 7 (G) (scale bar $100 \mu \mathrm{m})$.

The comparison with previously published results highlights that different cell types react oppositely to the embedding in the printed construct and might suggest that INS1E $\beta$-cells and islets of Langerhans are more sensitive than MSCs to hydrogel embedding. In vivo, islets in the pancreas are extensively vascularized in order to support their high metabolic activity, requiring constant and abundant glucose and oxygen supply for their normal functioning. On the contrary, MSCs normally reside in hypoxic environments in the body and are less metabolically active. This fact could explain why embedding in a porous hydrogel construct is beneficial for MSCs viability and metabolic activity [31], yet not enough for a more sensitive and metabolically requiring cell type as $\beta$-cells and islets of Langerhans.

The low INS1E metabolic activity and islet reduced functionality in the gel are indications that their activity is somehow limited by the material in which they are embedded. This is confirmed by the restored islet functionality when retrieved from the gel. According to these data, the major limitations that the plotting of cell-laden constructs still encounters is the availability of a suitable material capable of proper mass transport properties to maintain cell functionality and having at the same time sufficient mechanical properties for a layer by layer processing.

The optimal material for plotting has to meet various requirements: high viscosity, fast crosslink, biocompatibility, mechanical properties comparable with soft tissues and, once crosslinked, permeability to metabolites and catabolites. For plotting purposes the material has to be viscous enough to be plotted on subsequent layers on top of each other without collapsing under its own weight: such a highly viscous material restricts mass transport in the material itself, resulting in a limitation for islets functionality. To date, limited materials are available for cell-laden plotting purposes [52-54], and finding a compromise between mechanical properties for plotting, matrix stiffness, nutrient diffusion and functionality of embedded cells is still rather challenging [55]. The main limitations in the hydrogel used for this study are given by nutrient diffusion in such a viscous and highly concentrated gel. This study shows that the viability and functionality of embedded islets could be limitedly improved by a porous construct shape, if compared to solid bulk hydrogels. Islets showed functional response, although 

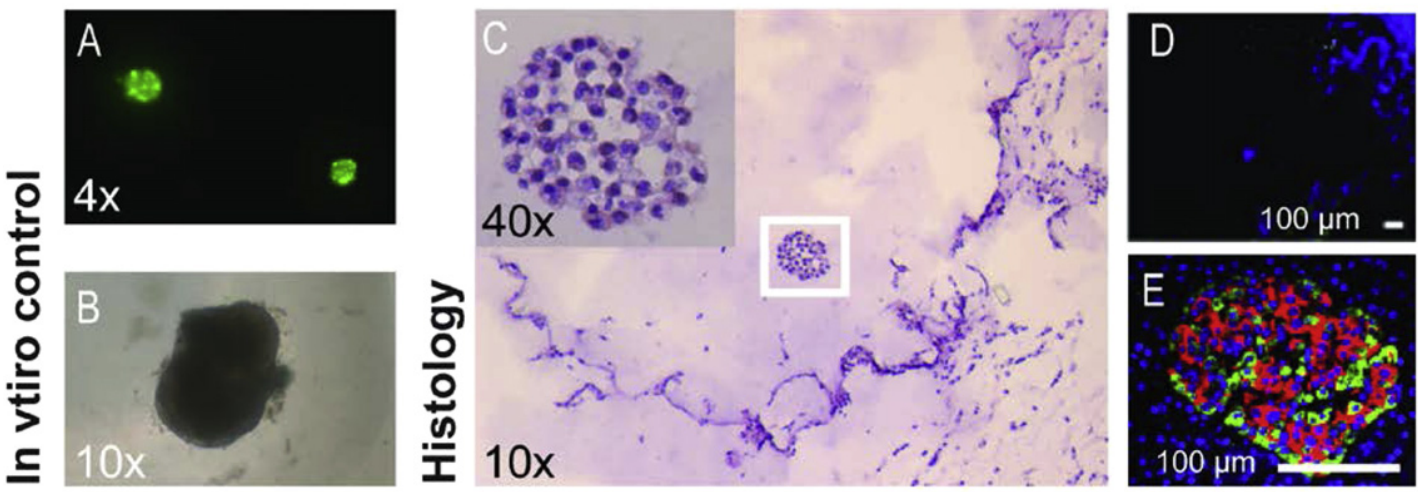

Figure 9. In vitro islet fluorescence was bright (A), and the morphology of the islets was preserved (B). After explant of the in vivo samples, islets were imaged with hematoxylin/eosin staining $(\mathrm{C})$, however no expression of insulin or glucagon was detected by immunostaining (D) compared to pancreas sections (E) (red: insulin, green: glucagon, blue: DAPI. Scale bar $100 \mu \mathrm{m}$ ).

reduced, at day one in the porous constructs while no functional behavior was observed in the bulk constructs at this time point (figure 6(B)). This shows that the plotted porous design can offer an improvement, although still limited, for nutrient diffusion in the gel. The reduced mass transport still remains a major limitation to the applicability of this technique to a scaffold of a clinically relevant size.

This is particularly true for islets of Langerhans, since they have very peculiar and demanding metabolic requirements and thus, they are more sensitive to the surrounding environment. In their native state, islets of Langerhans extensive vascularization provides for proper glucose sensing and insulin secretion and this characteristic is essential for their proper functionality. If this exchange is limited by the tight surrounding matrix, as it happens when islets are embedded in the alginate/gelatin mixture, islet functionality is hampered. Islets are viable in the hydrogel construct, but their ability to detect changes in glucose concentration and respond with proper insulin secretion is reduced by the tight matrix in which they are embedded. Islets are fully functional again when retrieved from the hydrogel construct and this confirms that the apparent loss of functionality is caused by limited mass transport through the gel.

The retrieved islet functionality after dissolution of the gel also excludes that the islets were damaged by the shear stress experienced during printing. It is reported in literature that a mechanical stress could permanently damage islet functionality, but in that case the functionality could not be retrieved simply by dissolving the surrounding gel.

As shown by the bead distribution in the plotted gel, the great majority of the beads is located at less than $200 \mu \mathrm{m}$ from the interface, less than the oxygen diffusion limit through tissues. Yet, the glucose diffusion coefficient measured in our system $\left(1.13 \times 10^{-6} \mathrm{~cm}^{2} \mathrm{~s}^{-1}\right)$ is significantly lower than glucose diffusion in water $\left(6.7 \times 10^{-6} \mathrm{~cm}^{2} \mathrm{~s}^{-1}\right)$ [43] and in $4 \%$ alginate solution only $\left(5 \times 10^{-6} \mathrm{~cm}^{2} \mathrm{~s}^{-1}\right)$ [39].
Such limited glucose diffusion in the construct is explained by a crosslinking obtained in saturation condition and by the presence of gelatin. The mesh size of a $4 \% \mathrm{w} / \mathrm{v}$ alginate solution has been reported to be around $7 \mathrm{~nm}$ [56], but the presence of gelatin as a interpenetrating network decreases consistently the number, diameter and length of the pores in an alginate hydrogel. This accounts for a considerable delay in glucose supply to the islets and a corresponding delay in insulin secretion from the hydrogel. Moreover, given the higher molecular weight and bigger hydrodynamic radius of an insulin molecule, the limitations experienced in insulin diffusion through the gel would be even more severe. Limited diffusion coefficients can explain the low metabolic activity, together with the apparent lack of functionality of the embedded cells. Moreover, the diffusion coefficient $D$ increases with the second power of the gel thickness $\left(D=l^{2} / 6 t\right)$. This means that for a small decrease in the gel thickness, a bigger increase in the diffusion coefficient is expected. This would explain why islets embedded in the plotted construct show some reduced functionality at day one, which is already completely absent in bulk constructs. This emphasizes the importance of construct design for islets functionality.

The effect of calcium ions used for crosslinking on insulin secreting pathways was also investigated as one of the possible reasons to explain INS1E and islet loss of functionality in the construct. As showed by many authors, voltage gated calcium channels, and consequently trans membrane calcium ion gradient are involved in insulin secretion mechanism [45, 46, 57]. Since the extracellular gel environment is quite rich in calcium ion concentration (102 mM crosslinking), the increased calcium concentration of the extracellular compartment might have caused the increased insulin secretion in low glucose condition. Although no difference in functionality was shown when hydrogels were crosslinked with other divalent cations, different concentrations or with reduced exposure times. 
To further study whether encapsulated islets maintained their viability in vivo, we implanted plotted constructs subcutaneously in nude mice and monitored their viability by intravital imaging. This is a powerful technique for in vivo follow up of transplanted tissue, enabling the imaging of the same transplanted islet in consecutive imaging sessions and study the process of revascularization of the scaffold. Intravital imaging has been applied to transplanted islets implanted under the kidney capsule [58] or in the anterior chamber of the eye $[59,60]$, which is a highly vascularized location. Here we show for the first time the applicability of this technique for the imaging of subcutaneously transplanted tissue in an implantable scaffold. In this kind of application, the presence of the window on top of the construct and the poorly vascularized location can furthermore limit oxygen diffusion to the transplanted tissue and islets are not anymore surrounded by tissue and blood vessels from all directions but only from the bottom. Consequently, nutrient diffusion to the islets located in the upper parts of the scaffolds has to rely solely on nutrient supply from the bottom part of the construct. This is even more important if we consider that the imaging depth of this intravital imaging model is also limited to $450 \mu \mathrm{m}$, which allow us to monitor only the upper layers of the hydrogel, the ones which suffer the most for lack of oxygen diffusion. Despite these limitations, we were still able to detect GFP expression and image islets for seven days in the construct, although islets showed signs of reduced GFP expression at later time points. This result correlates with our assumption of a reduced metabolic activity of the embedded cells, caused by an increased nutrient diffusion limitation in our model which was even more pronounced when an imaging window was used. Thus, both in vitro and in vivo results show that the plotting of islets is possible but the material optimization for this application is crucial to allow proper metabolite exchange with the embedded tissue.

In contrast to conventional islet encapsulation, here islets are confined in one location and after transplantation, blood vessels might grow through the pores of the construct, in closer contact with the embedded islets compared to the inner part of a bulk hydrogel scaffold. Potentially, an immunoprotective scaffold could be developed by using a non-degradable hydrogel, with a proper mesh size capable to block antibodies and cells of the immune system and the same time large enough to allow insulin diffusion.

\section{Conclusions}

This study demonstrated that 3D hydrogel plotting can be a valuable technique to couple islet embedding in hydrogel strandswith a pre-defined 3D scaffold architecture. $4 \%$ alginate $/ 5 \%$ gelatin was found to be a suitable hydrogel mixture for plotting of islets and $\beta$ cells, without compromising their viability and morphology. However, the high viscosity of the material needed for plotting, resulted in a dense mesh size, which impairs glucose diffusion and limits islet functionality. Since a highly viscous biomaterial is needed for plotting, a compromise has to be established between material properties allowing scaffold plotting and sufficient nutrient diffusion. Plotted hydrogels could effectively increase nutrient diffusion compared to the same bulk hydrogel, but the macro porous structure is not enough to overcome limitations caused by an insufficient diffusion of nutrients in this specific gel composition.

Despite the limitations in islet functionality when embedded in the construct, islets restored full functionality when retrieved from the hydrogel. In conclusion, plotting can be a powerful technique to engineer complex constructs, containing a clinically relevant number of islets. Although promising, the potential of the technique is currently hampered by scarce availability of suitable biomaterials. Further research is needed to develop hydrogels with sufficient viscosity and mechanical properties suitable for plotting but also with the capacity to support sufficient nutrient and secretory product diffusion for a physiologically relevant islet functionality.

\section{Acknowledgments}

This research is part of the Diabetes Cell Therapy Initiative (DCTI) and funded by the Dutch Diabetes research foundation and the Ministry of economical affairs (FES program) of the Netherlands. The authors acknowledge Dr Paul the Vos for kindly providing the ultrapure alginate.

\section{References}

[1] Ryan E A et al 2001 Clinical outcomes and insulin secretion after islet transplantation with the edmonton protocol Diabetes $50710-9$

[2] Shapiro A M J et al 2000 Islet transplantation in seven patients with type 1 diabetes mellitus using a glucocorticoid-free immunosuppressive regimen New England J. Med. 343 230-8

[3] Mallett A G and Korbutt G S 2009 Alginate modification improves long-term survival and function of transplanted encapsulated islets Tissue Eng. A 15 1301-9

[4] Bennet W et al 1999 Incompatibility between human blood and isolated islets of Langerhans: a finding with implications for clinical intraportal islet transplantation? Diabetes 48 1907-14

[5] Paraskevas S, Maysinger D, Wang R, Duguid W P and Rosenberg L 2000 Cell loss in isolated human islets occurs by apoptosis Pancreas 20 270-6

[6] Thomas F, Wu J, Contreras J L, Smyth C, Bilbao G, He J and Thomas J 2001 A tripartite anoikis-like mechanism causes early isolated islet apoptosis Surgery 130 333-8

[7] Thomas F T, Contreras J L, Bilbao G, Ricordi C, Curiel D and Thomas J M 1999 Anoikis, extracellular matrix, and apoptosis factors in isolated cell transplantation Surgery 126 299-304

[8] Lai Y et al 2005 Vascular endothelial growth factor increases functional [beta]-cell mass by improvement of angiogenesis of 
isolated human and murine pancreatic islets Transplantation 79 1530-6

[9] Pileggi A, Molano R D, Ricordi C, Zahr E, Collins J, Valdes R and Inverardi L 2006 Reversal of diabetes by pancreatic islet transplantation into a subcutaneous, neovascularized device Transplantation 81 1318-24

[10] Shapiro A M J, Gallant H L, Hao E G, Lakey J R T, McCready T, Rajotte R V, Ray V, Yatscoff R W and Kneteman N M 2005 The portal immunosuppressive storm: relevance to islet transplantation? Therapeutic Drug Monit. 27 35-7

[11] Billaudel B and Sutter B C J 1982 Immediate in vivo effect of corticosterone on glucose-induced insulin secretion in the rat J. Endocrinology 95 315-20

[12] Blomeier H, Zhang X, Rives C, Brissova M, Hughes E, Baker M, Powers A C, Kaufman D B, Shea L D and Lowe W L 2006 Polymer scaffolds as synthetic microenvironments for extrahepatic islets transplantation Transplantation 82 452-9

[13] Dufour J M, Rajotte R V, Zimmerman M, Rezania A, Kin T, Dixon D E and Korbutt G S 2005 Development of an ectopic site for islet transplantation, using biodegradable scaffolds Tissue Eng 11 1323-31

[14] Mao G H, Chen G A, Bai H Y, Song T R and Wang Y X 2009 The reversal of hyperglycaemia in diabetic mice using PLGA scaffolds seeded with islet-like cells derived from human embryonic stem cells Biomaterials 30 1706-14

[15] Daoud J T, Petropavlovskaia M S, Patapas J M, Degrandpré C E, DiRaddo R W, Rosenberg L and Tabrizian M 2011 Long-term in vitro human pancreatic islet culture using three-dimensional microfabricated scaffolds Biomaterials 32 1536-42

[16] Brady A C, Martino M M, Pedraza E, Sukert S, Pileggi A, Camillo R, Hubbell J A and Stabler C L 2013 Pro-angiogenic hydrogels within macroporous scaffolds enhances islet engraftment in an extrahepatic site Tissue Eng. A 19 2544-52

[17] Pedraza E, Brady A C, Fraker C A, Molano R D, Sukert S, Berman D M, Kenyon N S, Pileggi A, Ricordi C and Stabler C L 2013 Macroporous three-dimensional PDMS scaffolds for extrahepatic islet transplantation Cell Transplant 22 1123-35

[18] Buitinga M, Truckenmüller R, Engelse M A, Moroni L, Ten Hoopen H W M, van Blitterswijk C A, de Koning E J P, van Apeldoorn A A and Karperien M 2013 Microwell scaffolds for the extrahepatic transplantation of islets of Langerhans PLoS One 8 e64772

[19] Slaughter B V, Khurshid S S, Fisher O Z, Khademhosseini A and Peppas N A 2009 Hydrogels in regenerative medicine Adv. Mater. 21 3307-29

[20] Zhu J and Marchant R E 2011 Design properties of hydrogel tissue-engineering scaffolds Expert Rev. Med. Devices 8 607-26

[21] Lin C C and Anseth K S 2009 Glucagon-like peptide-1 functionalized peg hydrogels promote survival and function of encapsulated pancreatic $\beta$-cells Biomacromolecules 10 2460-7

[22] Zieris A, Prokoph S, Levental K R, Welzel P B, Grimmer M, Freudenberg U and Werner C 2010 FGF-2 and VEGF functionalization of starPEG-heparin hydrogels to modulate biomolecular and physical cues of angiogenesis Biomaterials 31 7985-94

[23] Lin C C and Anseth K S 2011 Cell-cell communication mimicry with poly(ethylene glycol) hydrogels for enhancing $\beta$ cell function Proc. Natl Acad. Sci. 108 6380-5

[24] de Vos P, Faas M M, Strand B and Calafiore R 2006 Alginatebased microcapsules for immunoisolation of pancreatic islets Biomaterials 27 5603-17

[25] de Vos P, Hamel A F and Tatarkiewicz K 2002 Considerations for successful transplantation of encapsulated pancreatic islets Diabetologia 45 159-73

[26] De Vos P, De Haan B J, Wolters G H J, Strubbe J H and Van Schilfgaarde R 1997 Improved biocompatibility but limited graft survival after purification of alginate for microencapsulation of pancreatic islets Diabetologia 40 262-70

[27] Ludwig B et al 2013 Transplantation of human islets without immunosuppression Proc. Natl Acad. Sci. 110 19054-8
[28] Cui X, Breitenkamp K, Finn M G, Lotz M and D'Lima D D 2012 Direct human cartilage repair using three-dimensional bioprinting technology Tissue Eng. A 18 1304-12

[29] Roth E A, Xu T, Das M, Gregory C, Hickman J J and Boland T 2004 Inkjet printing for high-throughput cell patterning Biomaterials 25 3707-15

[30] Wang Xet al 2006 Generation of three-dimensional hepatocyte/gelatin structures with rapid prototyping system Tissue Eng. 12 83-90

[31] Fedorovich N E, Kuipers E, Gawlitta D, Dhert W J and Alblas J 2011 Scaffold porosity and oxygenation of printed hydrogel constructs affect functionality of embedded osteogenic progenitors Tissue Eng. A 17 2473-86

[32] Hockaday L A et al 2012 Rapid 3D printing of anatomically accurate and mechanically heterogeneous aortic valve hydrogel scaffolds Biofabrication 4 1758-5082

[33] Cui X and Boland T 2009 Human microvasculature fabrication using thermal inkjet printing technology Biomaterials 30 6221-7

[34] Xu T, Rohozinski J, Zhao W, Moorefield E C, Atala A and Yoo J J 2009 Inkjet-mediated gene transfection into living cells combined with targeted delivery Tissue Eng. A 15 95-101

[35] Lee W, Pinckney J, Lee V, Lee J H, Fischer K, Polio S, Park J K and Yoo S S 2009 Three-dimensional bioprinting of rat embryonic neural cells Neuroreport 20 798-803

[36] Lee W 1, Debasitis J C, Lee V K, Lee J H, Fischer K, Edminster K, Park J K and Yoo S S 2009 Multi-layered culture of human skin fibroblasts and keratinocytes through threedimensional freeform fabrication Biomaterials 30 1587-95

[37] Saunders R E, Gough J E and Derby B 2008 Delivery of human fibroblast cells by piezoelectric drop-on-demand inkjet printing Biomaterials 29 193-203

[38] Fraga D W, Sabek O, Hathaway D K and Gaber A O 1998 A comparison of media supplement methods for the extended culture of human islet tissue Transplantation 65 1060-6

[39] Hannoun B J and Stephanopoulos G 1986 Diffusion coefficients of glucose and ethanol in cell-free and celloccupied calcium alginate membranes Biotechnol. Bioeng. 28 829-35

[40] Rutherford S W and Do D D 1997 Review of time lag permeation technique as a method for characterisation of porous media and membranes Adsorption 3283-312

[41] Masuda K, Takegami K, An H, Kumano F, Chiba K, Andersson G B, Schmid T and Thonar E 2003 Recombinant osteogenic protein-1 upregulates extracellular matrix metabolism by rabbit annulus fibrosus and nucleus pulposus cells cultured in alginate beads J.Orthopaedic Res. 21 922-30

[42] Rouwkema J, Rivron N C and van Blitterswijk C A 2008 Vascularization in tissue engineering Trends Biotechnol. 26 434-41

[43] Longsworth L G 1953 Diffusion measurements, at 25, of aqueous solutions of amino acids, peptides and sugars J. Am. Chem. Soc. 75 5705-9

[44] Simpson N E, Grant S C, Gustavsson L, Peltonen V-M, Blackband S J and Constantinidis I 2006 Biochemical consequences of alginate encapsulation: a NMR study of insulin-secreting cells Biomaterials 27 2577-86

[45] Hales C N and Milner R D 1968 Cations and the secretion of insulin from rabbit pancreas in vitro J. Physiol. 199 177-87

[46] Proks P and Ashcroft F M 1995 Effects of divalent cations on exocytosis and endocytosis from single mouse pancreatic betacells J. Physiol. 487 465-77

[47] de Vos P, Spasojevic M, de Haan B J and Faas M M 2012 The association between in vivo physicochemical changes and inflammatory responses against alginate based microcapsules Biomaterials 33 5552-9

[48] Seyednejad H, Gawlitta D, Dhert W J, van Nostrum CF, Vermonden T and Hennink W E 2011 Preparation and characterization of a three-dimensional printed scaffold based on a functionalized polyester for bone tissue engineering applications Acta Biomater. 7 1999-2006

[49] Park S A, Lee S H and Kim W D 2011 Fabrication of porous polycaprolactone/hydroxyapatite (PCL/HA) blend scaffolds 
using a 3D plotting system for bone tissue engineering Bioprocess Biosyst. Eng. 34 505-13

[50] Weber L M, Lopez C G and Anseth K S 2009 Effects of PEG hydrogel crosslinking density on protein diffusion and encapsulated islet survival and function J. Biomed. Mater. Res. A 90A 720-9

[51] Hunt N C, Shelton R M and Grover L M 2009 Reversible mitotic and metabolic inhibition following the encapsulation of fibroblasts in alginate hydrogels Biomaterials 30 6435-43

[52] Fedorovich N E, Alblas J, de Wijn J R, Hennink W E, Verbout A J and Dhert W J 2007 Hydrogels as extracellular matrices for skeletal tissue engineering: state-of-the-art and novel application in organ printing Tissue Eng. 13 1905-25

[53] Fedorovich N E, De Wijn J R, Verbout A J, Alblas J and Dhert W J 2008 Three-dimensional fiber deposition of cellladen, viable, patterned constructs for bone tissue printing Tissue Eng. A 14 127-33

[54] Fedorovich N E, Swennen I, Girones J, Moroni L, van Blitterswijk C A, Schacht E, Alblas J and Dhert W J 2009 Evaluation of photocrosslinked Lutrol hydrogel for tissue printing applications Biomacromolecules 10 1689-96
[55] Brandl F, Sommer F and Goepferich A 2007 Rational design of hydrogels for tissue engineering: impact of physical factors on cell behavior Biomaterials 28 134-46

[56] Turco G, Donati I, Grassi M, Marchioli G, Lapasin R and Paoletti S 2001 Mechanical spectroscopy and relaxometry on alginate hydrogels: a comparative analysis for structural characterization and network mesh size determination Biomacromolecules 12 1272-82

[57] Merglen A, Theander S, Rubi B, Chaffard G, Wollheim C B and Maechler P 2004 Glucose sensitivity and metabolism-secretion coupling studied during two-year continuous culture in INS-1E insulinoma cells Endocrinology 145 667-78

[58] Nyqvist D et al 2011 Donor islet endothelial cells in pancreatic islet revascularization Diabetes $602571-7$

[59] Speier S et al 2008 Noninvasive in vivo imaging of pancreatic islet cell biology Nat. Med. 14574-8

[60] Speier S, Nyqvist D, Kohler M, Caicedo A, Leibiger I B and Berggren P O 2008 Noninvasive high-resolution in vivo imaging of cell biology in the anterior chamber of the mouse eye Nat. Protocols 3 1278-86

[61] Benhamou PY et al 2001 Human islet transplantation network for the treatment of type I diabetes: first data from the Swiss-French GRAGIL consortium (1999-2000) Diabetologia 44 859-64 